\title{
Differential pharmacology and clinical utility of empagliflozin in type 2 diabetes
}

This article was published in the following Dove Press journal:

Clinical Pharmacology:Advances and Applications

20 April 2016

Number of times this article has been viewed

\author{
Kashif M Munir' \\ Stephen N Davis ${ }^{2}$ \\ 'Division of Endocrinology, Diabetes, \\ and Nutrition, Center for Diabetes \\ and Endocrinology, ${ }^{2}$ Department of \\ Medicine, University of Maryland \\ School of Medicine, Baltimore, MD, \\ USA
}

\begin{abstract}
With rates of obesity and diabetes rising across the world, effective therapies to treat hyperglycemia and its associated comorbidities continue to be in demand. Empagliflozin is a highly selective sodium glucose transporter-2 inhibitor that improves serum glucose levels by inducing glucosuria. Taken orally, it is rapidly absorbed with linear pharmacokinetics consistent in Asian and Caucasian populations. Empagliflozin treatment demonstrates consistent reductions in hemoglobin A1c, fasting plasma glucose, body weight, and blood pressure in individuals with type 2 diabetes. Improvements in glycemic control and metabolic end points are evident with empagliflozin monotherapy, as add-on to oral hypoglycemics or add-on to insulin. The nonglycemic effects of empagliflozin with consistent improvements in blood pressure, body weight, and waist circumference provide additional rationale for use in patients with type 2 diabetes. Moreover, treatment with empagliflozin has recently shown significant reductions in both microvascular and macrovascular complications of diabetes.
\end{abstract}

Keywords: empagliflozin, type 2 diabetes, pharmacology, blood pressure, body weight, hemoglobin A1c, glucose

\section{Introduction}

The burgeoning pandemics of diabetes mellitus and obesity continue to cause global concern for the health of current and future generations. Worldwide, $9 \%$ of adults now have diabetes, of which $90 \%$ have type 2 diabetes mellitus (T2DM). ${ }^{1}$ Despite the continually increasing number of therapeutic choices in treating T2DM, a significant percentage of patients still do not reach optimal glycemic targets and thereby fail to mitigate the increased risk of vascular complications associated with diabetes. ${ }^{2}$ Cardiovascular disease continues to be a leading cause of morbidity and mortality for patients with diabetes, ${ }^{3,4}$ and microvascular tissue complications lead to significant morbidity. Achieving glycemic goals with classic therapies such as insulin and sulfonylurea (SU) is hampered by the side effects of weight gain and hypoglycemia. Newer classes of agents have capitalized on unique mechanistic actions whereby glycemic improvements can be achieved without an increased risk of hypoglycemia or weight gain. In fact, glucagon-like peptide-1 agonists and sodium glucose transporter-2 (SGLT2) inhibitors often lead to modest amounts of weight loss.

SGLT2 inhibitors are the latest class of oral agents to be approved in treating individuals with T2DM. Empagliflozin was approved by the US Food and Drug Administration in August 2014 as the most recently approved SGLT2 inhibitor in the US. ${ }^{5}$ The differential pharmacology, clinical utility, and tolerability of empagliflozin will be reviewed here. submit your manuscript | www.dovepress.com

Dovepress

http://dx.doi.org// 0.2147/CPAA.S77754 


\section{Mechanism of action and pharmacology of empagliflozin \\ Mechanism of action}

SGLT2 inhibitors effectively lower blood glucose by increasing glucosuria. SGLT2 is a high-capacity, low-affinity sodium-coupled glucose transporter located primarily in the nephron's apical membrane of the early proximal convoluted tubule (S1/S2 segment), where it is responsible for $\sim 90 \%$ of glucose reabsorption in the kidney. ${ }^{6}$ In contrast, SGLT1 is a low-capacity, high-affinity transporter found in the distal segment of the proximal convoluted tubule ( $\mathrm{S} 3$ segment), where it reabsorbs the remaining glucose not absorbed by SGLT2. The primary function of SGLT1 is glucose and galactose reabsorption in the small intestine. ${ }^{7}$ The function of SGLT1 as a glucose transporter in the kidney may, however, become more influential with the inhibition of SGLT2. Although in normal physiology, SGLT2 is responsible for an overwhelming majority of glucose reabsorption, with SGLT2 blockade, $\sim 50 \%-70 \%$ of filtered glucose is excreted, presumably due to increases in SGLT1 reabsorption of glucose "escaping" SGLT2. ${ }^{8}$ Other SGLTs (SGLTs 3, 4, 5, and 6) have a less well-understood role in glucose homeostasis. ${ }^{9}$

Normally functioning kidneys filter and reabsorb $\sim 180 \mathrm{~g}$ glucose/d, and glucosuria is typically not detected until plasma glucose level exceeds $180 \mathrm{mg} / \mathrm{dL}$. In T2DM, the renal maximum glucose transport capacity is increased, thereby allowing even greater glucose reabsorption and worsening of hyperglycemia. ${ }^{6}$ Since SGLT2 inhibitors induce glucosuria, the primary mechanism of action is insulin independent. However, improvements in insulin-mediated whole body glucose uptake shown via euglycemic-hyperinsulinemic clamp in individuals treated with dapagliflozin, likely due to amelioration of glucotoxicity, provide evidence that SGLT2 inhibition also has an indirect effect on insulin sensitivity. ${ }^{10}$

\section{Pharmacology}

Empagliflozin $\left(\mathrm{C}_{23} \mathrm{H}_{27} \mathrm{ClO}_{7}\right.$; molecular weight 450.9$)$ is an orally active, competitive inhibitor of SGLT2 with a high selectivity for SGLT2 $\left(\mathrm{IC}_{50}\right.$ of $\left.3.1 \mathrm{nM}\right)$ compared with all other SGLTs. Empagliflozin has $>2,500$-fold selectivity for SGLT2 vs SGLT1, greater than all the other SGLT2 inhibitors currently available in the US and Europe. ${ }^{9,11}$ Single oral doses of empagliflozin given orally to healthy Caucasian male volunteers from $0.5 \mathrm{mg}$ to $800 \mathrm{mg}$ showed no clinically significant side effects. Empagliflozin was rapidly absorbed in a dose-proportional manner, reaching peak levels in 1.0-2.1 hours, and dose-dependent increases in urinary glucose excretion were observed in doses up to $100 \mathrm{mg}$. Terminal elimination half-life was up to 13.1 hours. ${ }^{12}$ Empagliflozin $(25 \mathrm{mg}$ or $50 \mathrm{mg}$ ) given with a high-fat, high-calorie meal does not result in any clinically relevant changes in exposure, indicating that it can be effectively taken with or without food. ${ }^{12,13}$ Similarly, in 48 healthy male Japanese subjects, single escalating doses of empagliflozin, 1-100 mg, also showed rapid dose-proportional absorption, attaining peak plasma levels in 1.25-2.50 hours. The mean terminal elimination half-life was up to 11.7 hours. Exposure to empagliflozin was higher in Japanese subjects compared with Caucasians in the previous study; however, this was likely attributable to lower mean body weight of Japanese participants. Adverse effects were mild, including headache and somnolence, and no cases of hypoglycemia were reported. Plasma glucose levels were not different in empagliflozin- or placebo-treated individuals, which is to be expected in healthy subjects. ${ }^{14}$

In a 28-day study of patients with T2DM, empagliflozin given at $10 \mathrm{mg}, 25 \mathrm{mg}$, or $100 \mathrm{mg}$ daily compared to placebo demonstrated a dose-proportional increased peak plasma concentration ( $\sim 1.5$ hours after dose) with linear pharmacokinetics (PKs) over time. ${ }^{15}$ Steady-state concentration was reached at day 6 , and the mean terminal elimination half-life was up to 16.5 hours. Increases in urinary glucose excretion of up to $90 \mathrm{~g} / \mathrm{d}(\sim 40 \%-45 \%$ inhibition of glucose absorption) were observed and remained consistent over the 4-week study period, without a significant change in urine volume. Fasting plasma glucose (FPG) decreased by $30-39 \mathrm{mg} / \mathrm{dL}$ from baseline to day 28, and post oral glucose tolerance test reductions in plasma glucose were also observed (area under effect time curve from 1 hour to 5 hours of $136-252 \mathrm{mg} \cdot \mathrm{h} /$ dL). Reductions in hemoglobin A1c (HbA1c) were also observed in empagliflozin-treated individuals $(-0.22 \%$ to $-0.36 \%$ ); however, these changes were not statistically significant compared to placebo, likely due to the short duration of follow-up. Adverse effects were reported similarly in placebo- vs empagliflozin-treated individuals, with one case of balanitis and one case of genital pruritus reported in the empagliflozin group. ${ }^{15} \mathrm{~A}$ similar, shorter duration study of 8 days utilizing empagliflozin $(2.5 \mathrm{mg}, 10 \mathrm{mg}, 25 \mathrm{mg}$, or $100 \mathrm{mg}$ daily) in 48 patients with T2DM vs placebo also showed dose-dependent absorption with a peak plasma level at 1.5-3.0 hours, elimination half-life of up to 19 hours, and a biphasic decline of exposure levels. ${ }^{16}$ Similarly, urinary glucose excretion of up to $89.8 \mathrm{~g} / \mathrm{d}$ and reductions in FPG of $4.6 \%-13.2 \%$ in empagliflozin-treated subjects vs placebo were observed. No urogenital infections were noted in this short study, and adverse effects were mild with headache being most commonly reported. ${ }^{16}$ 
A 4-week placebo-controlled variable dose study $(1 \mathrm{mg} / \mathrm{d}, 5 \mathrm{mg} / \mathrm{d}, 10 \mathrm{mg} / \mathrm{d}$, or $25 \mathrm{mg} / \mathrm{d})$ in Japanese patients with T2DM showed urinary glucose excretion of up to $93.0 \mathrm{~g} / \mathrm{d}$ and improvements in placebo-subtracted FPG of 12.6-27.2 mg/dL. ${ }^{17}$ Similar times to peak plasma concentration and elimination half-life were noticed in this group of Japanese patients. HbA1c improved in all empagliflozintreated subjects vs placebo (placebo-subtracted improvements of $-0.24 \%-0.43 \%$ ), and changes were statistically significant in all but the $1 \mathrm{mg}$ group. Adverse events were reported with higher frequency in the empagliflozin group but were mild in nature, including mild hypoglycemia in two empagliflozin-treated subjects, one case of cystitis, and no cases of genital mycotic infections. ${ }^{17}$

Since some degree of renal impairment is present in up to one-third of patients with $\mathrm{T} 2 \mathrm{DM},{ }^{18}$ it is important to understand the effects of renal impairment on the PKs and pharmacodynamics of empagliflozin. Glucuronidation is the major metabolic pathway for empagliflozin without major metabolites being detected in human plasma, and $\sim 11 \%-19 \%$ of empagliflozin is excreted unchanged in the urine. ${ }^{19}$ In an open-label trial of 40 subjects with progressive degrees of renal dysfunction, individuals were treated with a single dose of $50 \mathrm{mg}$ empagliflozin. Only subjects with normal renal function (estimated glomerular filtration rate [eGFR] $>90 \mathrm{~mL} / \mathrm{min} / 1.73 \mathrm{~m}^{2}$ ) were required to have T2DM, whereas individuals with an eGFR $<90 \mathrm{~mL} / \mathrm{min} / 1.73 \mathrm{~m}^{2} \mathrm{did}$ not need to have T2DM. The rate of absorption in subjects with any degree of renal impairment was slower than in those with normal renal function (2.0-2.5 hours vs 1.0 hour), and the mean terminal elimination half-life was longer in subjects with renal impairment ( 28 hours vs 20 hours). Renal clearance and fraction of dose excreted in urine also decreased with renal impairment, leading to an increase in area under the concentration-time curve of empagliflozin in plasma (by $18 \%, 20 \%, 66 \%$, and $48 \%$ in individuals with mild, moderate, and severe impairment and renal failure/ end-stage renal disease [ESRD], respectively). The maximum concentration of empagliflozin in plasma was $\sim 20 \%$ higher in subjects with mild or severe renal impairment when compared with individuals having normal renal function. ${ }^{19}$ Renal impairment was also associated with a slight decrease in plasma protein binding of empagliflozin from $85.1 \%$ with normal renal function to $81.1 \%$ in ESRD at 1.5 hours postdose, resulting in a $27 \%$ increase in the unbound fraction of empagliflozin. As expected, the total amount of urinary glucose excretion over 24 hours postdose decreased from $97.6 \mathrm{~g}$ in individuals with normal renal function to $0.8 \mathrm{~g}$ in subjects with ESRD. Adverse effects were noted in four of 40 subjects, which were mild in intensity and resolved without treatment. ${ }^{19} \mathrm{~A}$ similar study was done in 32 Japanese subjects with normal renal function to severe renal impairment, but did not include individuals with ESRD, and only subjects with T2DM were enrolled and were given a single dose of $25 \mathrm{mg}$ of empagliflozin. ${ }^{20}$ Peak plasma concentrations were similar across all groups, with increased extent of exposure to empagliflozin with more severe renal impairment (28.8\%, $43.8 \%$, and $52.3 \%$ higher exposure in mild, moderate, and severe renal impairment groups, respectively). Decreases in clearance of empagliflozin and reduced urinary glucose excretion were observed with increasing degrees of renal impairment, with urinary glucose excretion falling from $75 \mathrm{~g}$ to $23.7 \mathrm{~g}$ in 24 hours in patients with normal renal function vs severe renal impairment. Only two subjects experienced side effects, which were reported as mild (decreased appetite and abdominal distension). ${ }^{20}$

A single dose of empagliflozin $50 \mathrm{mg}$ given to 32 subjects with mild, moderate, and severe hepatic impairment compared with 12 matched controls again showed rapid absorption and biphasic decline in plasma drug concentration, consistent and no different from individuals with normal glucose tolerance, T2DM, and renal impairment. ${ }^{21}$ Exposure as measured by the area under the plasma concentration-time curve $(10,800 \mathrm{nmol} \cdot \mathrm{h} / \mathrm{L}$ vs $19,000 \mathrm{nmol} \cdot \mathrm{h} / \mathrm{L}$ for normal hepatic function vs severe hepatic impairment) and maximum plasma concentration $(1,370 \mathrm{nmol} / \mathrm{L}$ vs $1,970 \mathrm{nmol} / \mathrm{L}$ for normal hepatic function vs severe hepatic impairment) increased with greater degrees of liver impairment. No major effects on terminal plasma half-life or fraction of empagliflozin excreted unchanged in the urine were observed with liver impairment; however, renal clearance in plasma from 0 hour to 24 hours did decrease with greater degrees of hepatic dysfunction. Protein binding of empagliflozin 1.5 hours after dosing decreased slightly from $85.2 \%$ in subjects with normal hepatic function to $83.4 \%$ in subjects with severe liver impairment. Adverse effects were again mild and infrequent. ${ }^{21}$

Riggs et $a^{22}$ demonstrated sex, age, plasma total protein levels, smoking, or alcohol history do not affect empagliflozin PK parameters. Race also appears to have limited effects on PK; however, Asian patients were found to have a $25 \%$ greater oral absorption constant. Weight was the only covariate with a noticeable effect on PK parameters of $\pm 30 \%$ using the 2.5th and 97.5th percentiles of observed weights; however, this was not deemed clinically significant, implying that no exposure-based dose adjustments are required for a majority of patients treated with empagliflozin. ${ }^{22}$ A summary of 
PK and pharmacodynamic properties of empagliflozin is presented in Table 1.

\section{Clinical utility and data using empagliflozin in T2DM}

Over the past several years, empagliflozin therapy in an increasing number of clinical trials has provided a robust clinical data set. The distinct advantage of using SGLT2 inhibitors in patients with T2DM is their insulin-independent mode of action allowing use across a wide spectrum of disease, from newly diagnosed patients to those with progressive beta-cell failure treated with multidrug therapy and insulin injections. Empagliflozin also offers the additional benefits of weight loss, low risk of hypoglycemia, and potential improvements in blood pressure, renovascular complications, and cardiovascular outcomes, which may or may not all be SGLT2 inhibitor class effects. Therefore, the clinical utility of SGLT2 inhibitors in treating T2DM is vast, and future studies may define a broader role than solely glycemic control.

\section{Monotherapy}

In a multinational, 12-week, Phase IIb study of 408 patients with T2DM who were either treatment naïve or after a 4-week washout period, empagliflozin $5 \mathrm{mg}, 10 \mathrm{mg}$, or $25 \mathrm{mg}$ daily was compared to placebo or open-label metformin therapy. ${ }^{23}$ There were dose-dependent decreases from baseline $\mathrm{HbA} 1 \mathrm{c}$ $(\sim 8 \%)$ of $-0.4 \%,-0.5 \%$, and $-0.6 \%$ in the $5 \mathrm{mg} / \mathrm{d}, 10 \mathrm{mg} / \mathrm{d}$,

Table I Pharmacokinetic and pharmacodynamic characteristics of empagliflozin when given orally at clinically available doses of either $10 \mathrm{mg} / \mathrm{d}$ or $25 \mathrm{mg} / \mathrm{d}$

\begin{tabular}{ll}
\hline $\begin{array}{l}\text { Pharmacokinetics and pharmacodynamics of empagliflozin } \\
\text { ( } \mathbf{0 - 2 5} \mathbf{~ m g / d )}\end{array}$ & \\
\hline High SGLT2 selectivity & $\mathrm{IC}_{50}$ of $3.1 \mathrm{nM}$ \\
SGLT2:SGLTI selectivity ratio & $2,500: 1$ \\
Time to peak absorption after oral intake & $1.5-2.1$ hours \\
Maximum plasma concentration & $226-722 \mathrm{nmol} / \mathrm{L}$ \\
Area under concentration-time curve & $\mathrm{I}, 550-6,180 \mathrm{nmol} \cdot \mathrm{h} / \mathrm{L}$ \\
Terminal elimination half-life & $7.8-14.3 \mathrm{hours}$ \\
Renal clearance over 72 hours & $21.1-41.1 \mathrm{~mL} / \mathrm{min}$ \\
Terminal elimination half-life with hepatic & $17.1-18.1 \mathrm{hours}$ \\
impairment (50 mg) & \\
Terminal elimination half-life with renal & $22.0-27.9 \mathrm{hours}$ \\
impairment (50 mg) & \\
Renal clearance over 72 hours with renal & $0.5-18.6 \mathrm{~mL} / \mathrm{min}$ \\
impairment (50 mg) & \\
Urinary glucose excretion over 24 hours & $\sim 40-90 \mathrm{~g} / \mathrm{d}$ \\
\hline
\end{tabular}

Note: Terminal elimination half-life with hepatic or renal impairment and renal clearance with renal impairment are shown for $50 \mathrm{mg} / \mathrm{d}$, since those studies were done with only one dose.

Abbreviations: SGLT2, sodium glucose transporter-2; SGLTI, sodium glucose transporter- $I ; I_{50}$, half maximal inhibitory concentration. and $25 \mathrm{mg} / \mathrm{d}$ empagliflozin groups, respectively, which were significant when compared to the placebo arm $(+0.09 \%$, $P<0.0001)$. There were also reductions in fasting blood glucose from baseline $(-23.2 \mathrm{mg} / \mathrm{dL},-29.0 \mathrm{mg} / \mathrm{dL}$, and $-30.1 \mathrm{mg} / \mathrm{dL}$ in the $5 \mathrm{mg} / \mathrm{d}, 10 \mathrm{mg} / \mathrm{d}$, and $25 \mathrm{mg} / \mathrm{d}$ empagliflozin groups, respectively) that were significant when compared to the placebo arm $(+0.7 \mathrm{mg} / \mathrm{dL}, P<0.0001)$. The mean body weight decreased significantly vs placebo $(P<0.001)$ in all empagliflozin-treated groups $(-1.81 \mathrm{~kg},-2.33 \mathrm{~kg}$, and $-2.03 \mathrm{~kg}$ in $5 \mathrm{mg} / \mathrm{d}, 10 \mathrm{mg} / \mathrm{d}$, and $25 \mathrm{mg} / \mathrm{d}$ groups, respectively, compared with the placebo arm $[-0.75 \mathrm{~kg}])$. A reduction in mean serum uric acid levels was also noted in subjects treated with empagliflozin $(-0.4 \mathrm{mg} / \mathrm{dL}$ to $-0.7 \mathrm{mg} / \mathrm{dL})$ compared with mild increases in both placebo and metformin arms. Adverse events were similar among groups (27\%-32\% overall in empagliflozin-treated subjects), with pollakiuria, thirst, and nasopharyngitis being most commonly reported in individuals treated with empagliflozin. Four patients treated with empagliflozin vs three treated with either placebo or metformin reported symptoms consistent with urinary tract infection (UTI). Five patients, all among empagliflozin groups, reported genital tract infections. ${ }^{23}$

In a 12-week Phase IIb trial, 547 patients with T2DM across 32 centers in Japan were randomized to receive $5 \mathrm{mg}$, $10 \mathrm{mg}, 25 \mathrm{mg}$, or $50 \mathrm{mg}$ of empagliflozin daily or placebo, with the primary end point being change in $\mathrm{HbA1c} .{ }^{24}$ At the end of 12 weeks, a reduction $(P<0.001)$ in HbA1c was seen in all empagliflozin-treated arms vs placebo $(+0.30 \%$ in the placebo arm and $-0.42 \%,-0.40 \%,-0.65 \%$, and $-0.61 \%$ in $5 \mathrm{mg}, 10 \mathrm{mg}, 25 \mathrm{mg}$, and $50 \mathrm{mg}$ empagliflozin arms, respectively). FPG also improved $(P<0.001)$ in all empagliflozin groups $(+4.06 \mathrm{mg} / \mathrm{dL}$ in the placebo arm and $-22.65 \mathrm{mg} / \mathrm{dL}$, $-25.28 \mathrm{mg} / \mathrm{dL},-33.70 \mathrm{mg} / \mathrm{dL}$, and $-32.54 \mathrm{mg} / \mathrm{dL}$ in $5 \mathrm{mg}$, $10 \mathrm{mg}, 25 \mathrm{mg}$, and $50 \mathrm{mg}$ empagliflozin arms, respectively). Subjects with baseline $\mathrm{HbA} 1 \mathrm{c} \geq 8.0 \%$ achieved greater benefits with empagliflozin therapy $(+0.30 \%$ in the placebo arm and $-0.63 \%,-0.60 \%,-1.02 \%$, and $-0.75 \%$ in $5 \mathrm{mg}, 10 \mathrm{mg}, 25 \mathrm{mg}$, and $50 \mathrm{mg}$ empagliflozin arms, respectively). This is similar to other oral hypoglycemic agents that achieve greater reductions in $\mathrm{HbA} 1 \mathrm{c}$ with higher baseline levels at study enrollment. Empagliflozin treatment also led to significant reductions in body weight $(P<0.001)$ after only 12 weeks of therapy $(-0.9 \mathrm{~kg}$ in the placebo arm and $-2.5 \mathrm{~kg},-2.6 \mathrm{~kg},-2.9 \mathrm{~kg}$, and $-3.1 \mathrm{~kg}$ in $5 \mathrm{mg}, 10 \mathrm{mg}$, $25 \mathrm{mg}$, and $50 \mathrm{mg}$ empagliflozin arms, respectively). Notably, $16 \%-33 \%$ of subjects had a $>5 \%$ reduction in body weight from baseline in only 12 weeks. Waist circumference also decreased by $-1.0 \mathrm{~cm}$ to $-1.4 \mathrm{~cm}$ in empagliflozin-treated 
individuals. Systolic blood pressure was lower after 12 weeks of empagliflozin treatment $(-1.47 \mathrm{mmHg},-4.20 \mathrm{mmHg}$, $-3.22 \mathrm{mmHg}$, and $-3.83 \mathrm{mmHg}$ compared with placebo in $5 \mathrm{mg}, 10 \mathrm{mg}, 25 \mathrm{mg}$, and $50 \mathrm{mg}$ empagliflozin arms, respectively), and diastolic blood pressure was only significantly lower $(-1.56 \mathrm{mmHg}, P<0.05)$ in the $10 \mathrm{mg} / \mathrm{d}$ empagliflozin arm vs placebo. Total cholesterol levels were not significantly different among the groups, but high-density lipoprotein (HDL) was slightly higher in empagliflozin groups vs baseline (+5.4-6.2 mg/dL), and low-density lipoprotein (LDL) cholesterol was only slightly higher in the empagliflozin $50 \mathrm{mg} / \mathrm{d}$ group $(+1.5 \mathrm{mg} / \mathrm{dL}, P<0.05)$. Triglycerides were lower vs baseline in all empagliflozin arms $(-10.6 \mathrm{mg} / \mathrm{dL}$ to $-27.5 \mathrm{mg} / \mathrm{dL}, P<0.02)$. Uric acid levels also decreased as seen in previous studies $(-0.62 \mathrm{mg} / \mathrm{dL}$ to $-0.91 \mathrm{mg} / \mathrm{dL}$ in empagliflozin groups vs placebo). Similar rates of adverse events were reported in all groups, with only two mild cases of hypoglycemia in empagliflozin-treated subjects, UTI in four patients (one in placebo arm and three in empagliflozintreated arms), and genital infection in three empagliflozintreated individuals (all men).

In a 40-week extension of the study in Japan, 532 individuals continued taking either empagliflozin $10 \mathrm{mg} / \mathrm{d}$ or $25 \mathrm{mg} / \mathrm{d}$ or were reallocated to these doses if originally receiving placebo or empagliflozin $5 \mathrm{mg} / \mathrm{d}$ or $50 \mathrm{mg} / \mathrm{d} .{ }^{25}$ Results confirmed durable glycemic lowering and weight loss with empagliflozin for 1 year. At the end of 52 weeks, changes in $\mathrm{HbA} 1 \mathrm{c}$ from baseline $(\sim 8 \%)$ were $-0.67 \%$ and $-0.86 \%$ with empagliflozin $10 \mathrm{mg} / \mathrm{d}$ and $25 \mathrm{mg} / \mathrm{d}$, respectively. $\mathrm{HbA} 1 \mathrm{c}$ reduction was again shown to be greater in individuals with baseline levels $\geq 8.0 \%(-0.73 \%$ and $-1.04 \%$ with empagliflozin $10 \mathrm{mg} / \mathrm{d}$ and $25 \mathrm{mg} / \mathrm{d}$, respectively). FPG declined by $24.7 \mathrm{mg} / \mathrm{dL}$ and $31.3 \mathrm{mg} / \mathrm{dL}$ with empagliflozin $10 \mathrm{mg} / \mathrm{d}$ and $25 \mathrm{mg} / \mathrm{d}$, respectively, as did body weight $(-3.1 \mathrm{~kg})$ in both groups. Approximately $37 \%$ of subjects had a $>5 \%$ reduction in body weight at the end of 52 weeks. Waist circumference $(-2.8 \mathrm{~cm})$, systolic blood pressure $(-2.5 \mathrm{mmHg}$ to $-2.9 \mathrm{mmHg})$, and diastolic blood pressure $(-2.0 \mathrm{mmHg}$ to $-2.9 \mathrm{mmHg})$ were also all lower at the end of study. Improvements in uric acid $(-0.74 \mathrm{mg} / \mathrm{dL})$, HDL cholesterol $(5.8-6.2 \mathrm{mg} / \mathrm{dL})$, and triglycerides $(-18.6 \mathrm{mg} / \mathrm{dL}$ to $-20.4 \mathrm{mg} / \mathrm{dL}$ ) were again noted; however, a modest decrease in LDL cholesterol $(-1.5 \mathrm{mg} / \mathrm{dL}$ to $-2.7 \mathrm{mg} / \mathrm{dL})$ was apparent at 52 weeks, in contrast to the initial 12-week phase, which did not show a significant change in the $10 \mathrm{mg} / \mathrm{d}$ and $25 \mathrm{mg} / \mathrm{d}$ groups but a very modest increase in LDL cholesterol in the $50 \mathrm{mg} / \mathrm{d}$ group. Adverse effects were reported by a majority of study participants by 52 weeks $(66.8 \%-70.8 \%)$ but were almost all mild to moderate in nature, with very few patients (total five) discontinuing treatment due to adverse reactions. Hypoglycemia was reported in only two cases, UTIs in $1.1 \%-2.6 \%$ of subjects, and genital infections in $0.8 \%-3.0 \%$ of subjects.

Empagliflozin $10 \mathrm{mg} / \mathrm{d}$ and $25 \mathrm{mg} / \mathrm{d}$ and the dipeptidyl peptidase-4 (DPP4) inhibitor sitagliptin $100 \mathrm{mg} / \mathrm{d}$ were compared to placebo in a randomized, 24-week, multicenter trial of 899 individuals with T2DM not on current diabetes treatment. ${ }^{26}$ At the end of 24 weeks, reductions in HbA1c compared with baseline were seen across all treatment arms $(-0.74 \%,-0.85 \%$, and $-0.73 \%$ in the empagliflozin $10 \mathrm{mg} / \mathrm{d}$ and $25 \mathrm{mg} / \mathrm{d}$ and sitagliptin groups, respectively, $P<0.0001$ vs placebo in all groups). In patients with $\mathrm{HbA1c}$ $\geq 8.5 \%$ at baseline, reductions in $\mathrm{HbA} 1 \mathrm{c}$ were significantly greater with empagliflozin $(-1.44 \%$ and $-1.43 \%$ in the empagliflozin $10 \mathrm{mg} / \mathrm{d}$ and $25 \mathrm{mg} / \mathrm{d}$ groups, respectively) vs sitagliptin (-1.04\%). FPG (-19.44 mg/dL, -24.48 mg/dL, and $-6.84 \mathrm{mg} / \mathrm{dL}$ in empagliflozin $10 \mathrm{mg} / \mathrm{d}$ and $25 \mathrm{mg} / \mathrm{d}$ and sitagliptin groups, respectively) and body weight $(-2.26 \mathrm{~kg}$, $-2.48 \mathrm{~kg}$, and $+0.18 \mathrm{~kg}$ in empagliflozin $10 \mathrm{mg} / \mathrm{d}$ and $25 \mathrm{mg} / \mathrm{d}$ and sitagliptin groups, respectively) were also lower in empagliflozin-treated individuals. Percentage of patients with a $>5 \%$ reduction in body weight was higher with empagliflozin therapy $(22.8 \%-29.0 \%)$ compared with sitagliptin (6.3\%). Systolic ( $-2.9 \mathrm{mmHg}$ to $-3.7 \mathrm{mmHg}$ vs $+0.5 \mathrm{mmHg})$ blood pressure and diastolic $(-1.0 \mathrm{mmHg}$ to $-1.9 \mathrm{mmHg}$ vs $+0.7 \mathrm{mmHg}$ ) blood pressure were also lower compared with baseline in patients receiving empagliflozin vs sitagliptin. Individuals with $\mathrm{HbA} 1 \mathrm{c}>10.0 \%$ at study enrollment were eligible to receive open-label empagliflozin $25 \mathrm{mg} / \mathrm{d}$. This group of 87 patients showed a mean $\mathrm{HbA} 1 \mathrm{c}$ reduction from $11.5 \%$ to $7.6 \%$ over 24 weeks. Reports of adverse events were similar across all groups and mild (61\% in the placebo arm, $53 \%-60 \%$ in active treatment arms). UTIs were reported in similar proportions across all groups, although women on empagliflozin had a greater number of events. Genital infections were more common with empagliflozin $(3 \%-4 \%)$ vs sitagliptin (1\%). Small increases in hematocrit and HDL cholesterol and a small decrease in mean uric acid were noted with empagliflozin therapy, but no significant changes in LDL cholesterol or triglycerides were observed.

In a 12-week trial designed to look at the effects of empagliflozin $10 \mathrm{mg} / \mathrm{d}$ or $25 \mathrm{mg} / \mathrm{d}$ on 24-hour ambulatory blood pressure in individuals with T2DM and hypertension, empagliflozin significantly lowered mean 24-hour systolic blood pressure $(+0.48 \mathrm{mmHg}$ in the placebo arm and $-2.95 \mathrm{mmHg}$ and $-3.68 \mathrm{mmHg}$ in the empagliflozin $10 \mathrm{mg} / \mathrm{d}$ and $25 \mathrm{mg} / \mathrm{d}$ 
arms, respectively) and diastolic blood pressure vs placebo $(+0.32 \mathrm{mmHg}$ in the placebo arm and $-1.04 \mathrm{mmHg}$ and $-1.40 \mathrm{mmHg}$ in the empagliflozin $10 \mathrm{mg} / \mathrm{d}$ and $25 \mathrm{mg} / \mathrm{d}$ arms, respectively). ${ }^{27}$ Placebo-subtracted reductions in seated office blood pressure were similar to ambulatory monitoring. $\mathrm{HbA} 1 \mathrm{c}(+0.03 \%$ in the placebo arm and $-0.59 \%$ and $-0.62 \%$ in the empagliflozin $10 \mathrm{mg} / \mathrm{d}$ and $25 \mathrm{mg} / \mathrm{d}$ arms, respectively) and body weight $(-0.18 \mathrm{~kg}$ in the placebo arm and $-1.68 \mathrm{~kg}$ and $-2.16 \mathrm{~kg}$ in the empagliflozin $10 \mathrm{mg} / \mathrm{d}$ and $25 \mathrm{mg} / \mathrm{d}$ arms, respectively) were also significantly lower in empagliflozintreated patients vs placebo at the end of 12 weeks. Adverse events were similar to previously reported studies ${ }^{23-26}$ with low rates of mild hypoglycemia and UTIs in all groups but higher rates of genital infection in empagliflozin-treated subjects $(5.1 \%-5.4 \%)$ vs placebo $(0.4 \%)$.

\section{Effects on glucose variability}

SGTL2 inhibitors are thought to have a "smoothing" effect on glucose levels, decreasing amplitude of glucose excursions. Variations in postprandial glucose and glucose are associated with risk of cardiovascular disease and activation of oxidative stress pathways. ${ }^{28-30}$ A study utilizing continuous glucose monitoring to evaluate the effects of empagliflozin $10 \mathrm{mg} / \mathrm{d}$ and $25 \mathrm{mg} / \mathrm{d}$ on the variability of postprandial glucose and 24-hour glucose in 60 Japanese subjects with T2DM showed an improvement in glycemic control but not in mean amplitude of glucose excursions. ${ }^{31}$ The area under glucose concentration-time curve 3 hours after a breakfast mixed meal improved significantly $(P<0.001)$ after one dose of empagliflozin compared with baseline $(-97.1 \mathrm{mg} \cdot \mathrm{h} / \mathrm{dL}$ and $-91.6 \mathrm{mg} \cdot \mathrm{h} / \mathrm{dL}$ for empagliflozin $10 \mathrm{mg}$ and $25 \mathrm{mg}$, respectively), and reduced postmeal glucose $(P<0.001)$ was maintained at day $28(-85.5 \mathrm{mg} \cdot \mathrm{h} / \mathrm{dL}$ and $-104.9 \mathrm{mg} \cdot \mathrm{h} /$ $\mathrm{dL}$ for empagliflozin $10 \mathrm{mg}$ and $25 \mathrm{mg}$, respectively), along with reduced 24-hour adjusted mean glucose $(-24.5 \mathrm{mg} / \mathrm{dL}$ and $-31.7 \mathrm{mg} / \mathrm{dL}$ for empagliflozin $10 \mathrm{mg}$ and $25 \mathrm{mg}$, respectively, $P<0.001$ vs placebo). The percentage of time spent with glucose $\geq 70-<180 \mathrm{mg} / \mathrm{dL}$ increased from baseline in subjects treated with both $10 \mathrm{mg} / \mathrm{d}$ of empagliflozin (52\%-77\%) and $25 \mathrm{mg} / \mathrm{d}$ of empagliflozin (55\%-81\%), without an increase in hypoglycemia. Even though the study was carried out for only 28 days, changes in HbA1c were evident $(-0.35 \%$ and $-0.52 \%$ vs placebo for empagliflozin $10 \mathrm{mg}$ and $25 \mathrm{mg}$, respectively, $P<0.001$ vs placebo). The excretion of 8 -iso-PGF2 $\alpha$, a marker of oxidative stress, was also significantly reduced while fasting in both $10 \mathrm{mg} / \mathrm{d}$ and $25 \mathrm{mg} / \mathrm{d}$ empagliflozin arms vs placebo but was only significantly lower in the $25 \mathrm{mg} / \mathrm{d}$ group in the 24 hours after drug administration. Small decreases in body weight and blood pressure were observed, but no changes in total or LDL cholesterol were seen. HDL did increase significantly and triglycerides decreased, but the short duration of the study period limits the value of these findings. Adverse events were again rare and mild with only one case of genital infection, no UTIs, and no diabetic ketoacidosis (DKA). Ketone bodies, however, did increase from baseline by $151.7 \mu \mathrm{mol} / \mathrm{L}$ and $420.2 \mu \mathrm{mol} / \mathrm{L}$ (10 mg/d and $20 \mathrm{mg} / \mathrm{d}$ groups, respectively), although DKA is typically accompanied by ketone bodies $>3,000 \mu \mathrm{mol} / \mathrm{L}^{32}$ Improvements in both fasting and postprandial glucose led to a downward shift in glucose curves, but no difference in mean glycemic excursion amplitudes.

\section{Combination therapy}

Empagliflozin has been studied as add-on therapy to most oral hypoglycemics and insulin. A 52-week study of empagliflozin $10 \mathrm{mg} / \mathrm{d}$ or $25 \mathrm{mg} / \mathrm{d}$ added on to 1,160 patients with T2DM on preexisting monotherapy with SU, metformin, thiazolidinedione, $\alpha$-glucosidase inhibitor, DPP4 inhibitor, or meglitinide across 86 centers in Japan demonstrated an $\mathrm{HbA} 1 \mathrm{c}$ reduction of $-0.77 \%$ to $-1.00 \%$ and improvements in fasting glucose ranging from $-16.4 \mathrm{mg} / \mathrm{dL}$ to $-33.1 \mathrm{mg} / \mathrm{dL}{ }^{33}$ Similar to prior studies with monotherapy, ${ }^{23-27}$ there were reductions in body weight $(-2.3 \mathrm{~kg}$ to $-3.9 \mathrm{~kg})$ and improvements in systolic blood pressure $(-4.5 \mathrm{mmHg}$ to $-7.4 \mathrm{mmHg})$ and diastolic blood pressure $(-2.3 \mathrm{mmHg}$ to $-3.6 \mathrm{mmHg})$. A group of patients on preexisting SU therapy were also randomized to receive open-label metformin therapy instead of empagliflozin, and changes in body weight, blood pressure, and fasting glucose were greater in empagliflozin groups vs add-on metformin group, whereas changes in $\mathrm{HbA} 1 \mathrm{c}$ from baseline were similar in individuals treated with either add-on therapy. Decreases in uric acid $(0.2-1.0 \mathrm{mg} / \mathrm{dL})$ were seen in empagliflozin patients vs increase of $0.5 \mathrm{mg} / \mathrm{dL}$ in subjects treated with add-on metformin. Decreases in total cholesterol $(6.3-15.7 \mathrm{mg} / \mathrm{dL})$ and triglycerides $(2.5-22.9 \mathrm{mg} / \mathrm{dL})$ were noted with add-on empagliflozin therapy, and increases in HDL cholesterol (4.8-8.2 $\mathrm{mg} / \mathrm{dL})$ and LDL cholesterol (1.6-8.1 mg/dL) were evident after 52 weeks. Adverse events were reported in $67.6 \%-84.6 \%$ of participants receiving add-on empagliflozin. Most were again mild, with only a $1.4 \%-7.4 \%$ discontinuation rate. Confirmed hypoglycemia was $0.0 \%-2.9 \%$ across all background therapies except for those on $\mathrm{SU}$, where hypoglycemic rates were expectedly higher, 4.4\%-6.6\%. Comparatively, subjects who were randomized to add-on metformin to SU had a confirmed hypoglycemia rate of $7.9 \%$. UTIs were more common in 
empagliflozin-treated women $(1.4 \%-7.4 \%)$, and genital infections were also increased with empagliflozin ranging from $0.0 \%$ to $5.9 \%$ in subjects. Volume depletion was rare, and small increases in hematocrit $(3.6 \%-5.5 \%)$ were observed consistent with prior studies.

An earlier dose-finding study of empagliflozin $1 \mathrm{mg} / \mathrm{d}$, $5 \mathrm{mg} / \mathrm{d}, 10 \mathrm{mg} / \mathrm{d}, 25 \mathrm{mg} / \mathrm{d}$, or $50 \mathrm{mg} / \mathrm{d}$, open-label sitagliptin $100 \mathrm{mg} / \mathrm{d}$, or placebo added to metformin for 12 weeks again showed significant reductions in $\mathrm{HbA} 1 \mathrm{c}(-0.09 \%$ to $-0.56 \%$ vs $-0.45 \%$ for sitagliptin), FPG ( $-2 \mathrm{mg} / \mathrm{dL}$ to $-28 \mathrm{mg} / \mathrm{dL})$, and body weight $(-2.3 \mathrm{~kg}$ to $-2.9 \mathrm{~kg}){ }^{34}$ Improvements in systolic blood pressure (up to $-8.5 \mathrm{mmHg}$ ) and diastolic blood pressure (up to $-4.2 \mathrm{mmHg}$ ) were again observed, with the greatest reduction in the $25 \mathrm{mg} / \mathrm{d}$ empagliflozin group. The mean serum uric acid values at study end declined in the empagliflozin groups from $-0.5 \mathrm{mg} / \mathrm{dL}$ to $-0.8 \mathrm{mg} / \mathrm{dL}$. Adverse events were rare, mild, and similar to those reported in previous trials. UTIs and genital infections were reported in $4 \%$ of empagliflozin-treated subjects, and hypoglycemia was rare and mild, 1.1\%. A 78-week open-label extension trial of the earlier study and Ferrannini et $\mathrm{al}^{23,34}$ study compared empagliflozin $10 \mathrm{mg} / \mathrm{d}$ or $25 \mathrm{mg} / \mathrm{d}$ monotherapy or as add-on to metformin with metformin monotherapy and sitagliptin $100 \mathrm{mg} / \mathrm{d}$ as add-on to metformin. ${ }^{35}$ Subjects previously on empagliflozin $10 \mathrm{mg} / \mathrm{d}$ or $25 \mathrm{mg} / \mathrm{d}$ continued on that dose, while other empagliflozin arms were rerandomized to either $10 \mathrm{mg} / \mathrm{d}$ or $25 \mathrm{mg} / \mathrm{d}$. Changes in HbAlc at week 90 were $-0.34 \%$ to $-0.63 \%$ with empagliflozin, $-0.56 \%$ with metformin, and $-0.40 \%$ with sitagliptin, and FPG declined by $-21 \mathrm{mg} / \mathrm{dL}$ to $-32 \mathrm{mg} / \mathrm{dL}$ with empagliflozin, $-26 \mathrm{mg} / \mathrm{dL}$ with metformin, and $-16 \mathrm{mg} / \mathrm{dL}$ with sitagliptin. Body weight decreased in all groups $(-2.2 \mathrm{~kg}$ to $-4.0 \mathrm{~kg}$ with empagliflozin, $-1.3 \mathrm{~kg}$ with metformin, and $-0.4 \mathrm{~kg}$ with sitagliptin). Modest improvements in waist circumference, systolic blood pressure, and diastolic blood pressure were noted but were not significant in all empagliflozin arms. Adverse events were again mostly mild, with $0.9 \%-2.4 \%$ of subjects showing hypoglycemia, $3.8 \%-12.7 \%$ of subjects showing UTIs, and $3.0 \%-5.5 \%$ of subjects having genital infections among empagliflozin-treated individuals. Interestingly, $12.5 \%$ of patients treated with sitagliptin also reported UTI.

In another multicenter, multinational add-on study to metformin, 637 subjects were randomized to either empagliflozin $10 \mathrm{mg} / \mathrm{d}$ or $25 \mathrm{mg} / \mathrm{d}$ or placebo, added on to metformin 1,500 mg/d. ${ }^{36}$ Significant mean changes in HbA1c after 24 weeks of treatment were observed at $-0.13 \%$ in the placebo arm and $-0.70 \%$ and $-0.77 \%$ in the empagliflozin $10 \mathrm{mg} / \mathrm{d}$ and $25 \mathrm{mg} / \mathrm{d}$ arms, respectively. A significant change in body weight also occurred $-0.45 \mathrm{~kg}$ in the placebo arm and $-2.08 \mathrm{~kg}$ and $-2.46 \mathrm{~kg}$ in empagliflozin $10 \mathrm{mg} / \mathrm{d}$ and $25 \mathrm{mg} / \mathrm{d}$ arms, respectively. Significant reductions in FPG $(+6.3 \mathrm{mg} / \mathrm{dL}$ in the placebo arm and $-20.0 \mathrm{mg} / \mathrm{dL}$ and $-22.3 \mathrm{mg} / \mathrm{dL}$ in empagliflozin $10 \mathrm{mg} / \mathrm{d}$ and $25 \mathrm{mg} / \mathrm{d}$ arms, respectively), 2-hour postprandial glucose $(+5.9 \mathrm{mg} / \mathrm{dL}$ in the placebo arm and $-45.9 \mathrm{mg} / \mathrm{dL}$ and $-44.5 \mathrm{mg} / \mathrm{dL}$ in empagliflozin $10 \mathrm{mg} / \mathrm{d}$ and $25 \mathrm{mg} / \mathrm{d}$ arms, respectively), and mean daily glucose utilizing 8 -point daily glucose profile $(-2.0 \mathrm{mg} / \mathrm{dL}$ in the placebo arm and $-9.7 \mathrm{mg} / \mathrm{dL}$ and $-14.4 \mathrm{mg} / \mathrm{dL}$ in empagliflozin $10 \mathrm{mg} / \mathrm{d}$ and $25 \mathrm{mg} / \mathrm{d}$ arms, respectively) were also demonstrated. Waist circumference was $\sim 1 \mathrm{~cm}$ less after 24 weeks in empagliflozin-treated patients vs placebo. Significant changes in systolic blood pressure $(-0.4 \mathrm{mmHg}$ in the placebo arm and $-4.5 \mathrm{mmHg}$ and $-5.2 \mathrm{mmHg}$ in empagliflozin $10 \mathrm{mg} / \mathrm{d}$ and $25 \mathrm{mg} / \mathrm{d}$ arms, respectively) and diastolic blood pressure $(0.0 \mathrm{mmHg}$ in the placebo arm and $-2.0 \mathrm{mmHg}$ and $-1.6 \mathrm{mmHg}$ in empagliflozin $10 \mathrm{mg} / \mathrm{d}$ and $25 \mathrm{mg} / \mathrm{d}$ arms, respectively) were also observed. Individuals with $\mathrm{HbA} 1 \mathrm{c}>10 \%$ were eligible to participate in an open-label empagliflozin $25 \mathrm{mg} / \mathrm{d}$ arm. At week 24 compared with baseline, these subjects had a very robust lowering of HbA1c of $-3.23 \%$, FPG $(-54.4 \mathrm{mg} / \mathrm{dL})$, and mean daily glucose $(-76.2 \mathrm{mg} / \mathrm{dL})$, while changes in other parameters were similar to remaining subjects treated with empagliflozin. Adverse events were reported by $95 \%$ of study participants but were of mild to moderate intensity. Hypoglycemia was noted in a total of seven individuals receiving empagliflozin. UTIs were reported in $4.9 \%-5.6 \%$ of patients in all groups (more so in women) and genital infections in 3.7\%-4.7\% of empagliflozin-treated patients only (also more commonly in women). Hematocrit, uric acid, and lipid changes were consistent with previously described studies. A 52-week extension study included 463 of 637 participants in the 24-week study. ${ }^{37}$ Significant $\mathrm{HbA} 1 \mathrm{c}$ reductions were maintained at the end of week $76(-0.6 \%$ and $-0.7 \%$ for empagliflozin $10 \mathrm{mg} / \mathrm{d}$ and $25 \mathrm{mg} / \mathrm{d}$, respectively), as were placebo-subtracted changes in body weight $(-1.9 \mathrm{~kg}$ and $-2.2 \mathrm{~kg}$ for empagliflozin $10 \mathrm{mg} / \mathrm{d}$ and $25 \mathrm{mg} / \mathrm{d}$, respectively). Significant changes in systolic blood pressure $(-3.7 \mathrm{mmHg}$ to $-4.4 \mathrm{mmHg}$ ) remained after 76 weeks, but not diastolic blood pressure. Adverse effects included hypoglycemia (reported in $3.4 \%$ of participants on placebo and $4.1 \%$ and $4.2 \%$ of participants on empagliflozin $10 \mathrm{mg}$ and empagliflozin $25 \mathrm{mg}$, respectively), UTIs (not significantly higher in empagliflozin groups and in fact lower in subjects treated with $25 \mathrm{mg} / \mathrm{d}$ ), and genital infections (8.3\%-9.3\% vs $0.5 \%$ in empagliflozin- vs placebo-treated individuals). Small increases in hematocrit, decreases in uric 
acid, increases in total cholesterol and HDL, and no changes in LDL or triglycerides were seen.

In a 2-year, Phase III study of 1,549 subjects evaluating empagliflozin $25 \mathrm{mg} / \mathrm{d}$ or glimepiride $1-4 \mathrm{mg} / \mathrm{d}$ as add-on therapy to metformin, empagliflozin was noninferior to glimepiride at both 52 weeks and 104 weeks. ${ }^{38}$ Glimepiride was initiated at $1 \mathrm{mg} / \mathrm{d}$ and titrated over the first 12 weeks based on fasting glucose response. The mean dose of glimepiride was relatively low at $2.71 \mathrm{mg} / \mathrm{d}$. HbA1c changes were significant vs baseline at 52 weeks $(-0.66 \%$ and $-0.73 \%$ for glimepiride and empagliflozin, respectively) and 104 weeks $(-0.55 \%$ and $-0.66 \%$ for glimepiride and empagliflozin, respectively). The $-0.11 \%$ lower $\mathrm{HbA} 1 \mathrm{c}$ for empagliflozin-treated patients at 104 weeks was significantly superior to glimepiride treatment $(P=0.0153)$. Patients with initial $\mathrm{HbA} 1 \mathrm{c} \geq 8.5 \%$ showed an even further reduction of $-1.22 \%$ with empagliflozin therapy compared with a reduction of $-0.93 \%$ with glimepiride. At 104 weeks, FPG (-3.06 mg/dL vs $-15.3 \mathrm{mg} / \mathrm{dL}$ for glimepiride vs empagliflozin, respectively) and body weight (difference $-4.61 \mathrm{~kg}$ ) were also lower compared with baseline with add-on empagliflozin vs glimepiride. Systolic blood pressure declined by $-3.1 \mathrm{mmHg}$ in the empagliflozin group compared with an increase from baseline of $2.5 \mathrm{mmHg}$ in patients treated with glimepiride at the end of 2 years. Diastolic blood pressure was also lower at 2 years with empagliflozin by $-1.9 \mathrm{mmHg}$ vs a $0.9 \mathrm{mmHg}$ increase with glimepiride. Interestingly, dual energy X-ray absorptiometry scans done on a subset of patients showed that $\sim 90 \%$ of the weight loss with empagliflozin was due to a reduction in fat mass, and magnetic resonance imaging scans demonstrated that fat loss occurred in both abdominal visceral and subcutaneous fat tissues. Adverse events were similarly reported in both groups with higher rates of confirmed hypoglycemia in glimepiride- vs empagliflozin-treated patients $(24 \%$ vs $2 \%$ ). UTIs were reported in similar proportions of patients (13\% with glimepiride and 14\% with empagliflozin), but genital infections were more common with empagliflozin therapy (12\% vs $2 \%$ ). Renal function did not change with empagliflozin from baseline compared with 104 weeks. Hematocrit, total cholesterol, LDL cholesterol, and HDL cholesterol all increased slightly with empagliflozin compared with glimepiride.

Patients inadequately controlled on metformin and SU therapy were randomized to receive either placebo or empagliflozin $10 \mathrm{mg} / \mathrm{d}$ or $25 \mathrm{mg} / \mathrm{d} .{ }^{39}$ Empagliflozin was shown to be effective as triple therapy in reducing HbA1c $(-0.17$, $-0.82,-0.77)$ and body weight $(-0.39 \mathrm{~kg}$ in the placebo arm and $-2.16 \mathrm{~kg}$ and $-2.39 \mathrm{~kg}$ in empagliflozin $10 \mathrm{mg} / \mathrm{d}$ and $25 \mathrm{mg} / \mathrm{d}$ arms, respectively). Empagliflozin effectively lowered $\mathrm{HbA} 1 \mathrm{c}$ at the end of 24 weeks in patients with mildto-moderate renal impairment as well, albeit to a lesser degree. Reductions in waist circumference $(-1.15 \mathrm{~cm}$ to $-1.17 \mathrm{~cm}$ vs placebo), FPG (-28.8 mg/dL vs placebo), 2-hour postprandial glucose $(-33.5 \mathrm{mg} / \mathrm{dL}$ to $-34.5 \mathrm{mg} / \mathrm{dL}$ vs placebo), and mean daily glucose $(-10.1 \mathrm{mg} / \mathrm{dL}$ to $-14.2 \mathrm{mg} / \mathrm{dL}$ vs placebo) were also demonstrated with empagliflozin therapy. A small significant decrease in systolic blood pressure but not diastolic blood pressure was observed. An open-label group of patients with $\mathrm{HbA1c}>10 \%$ who received empagliflozin $25 \mathrm{mg} / \mathrm{d}$ again showed a robust $\mathrm{HbA} 1 \mathrm{c}$ decline of $-2.89 \%$. Adverse events were more common in empagliflozin-treated subjects with confirmed rates of hypoglycemia (11.5\%-16.1\% compared with $8.4 \%$ in placebo). UTIs were reported by $8 \%$ of patients on placebo vs $8.3 \%$ on $25 \mathrm{mg} / \mathrm{d}$ of empagliflozin and $10.3 \%$ on empagliflozin of $10 \mathrm{mg} / \mathrm{d}$, and genital infections were reported by $2.3 \%-2.7 \%$ of patients in empagliflozin groups vs $0.9 \%$ of patients in the placebo group. UTIs and genital infections were both more common in women than men. Again no changes in electrolytes and minor changes in hematocrit, lipids, and uric acid were noted similar to prior studies. In a 52-week extension of this trial, 472 of 666 patients continued therapy, and reductions in $\mathrm{HbA1c}$ were maintained at $-0.7 \%$ in both empagliflozin groups vs placebo, along with reduction in body weight of $1.6-1.8 \mathrm{~kg}$ in empagliflozin groups vs placebo at 76 weeks. ${ }^{40}$ Adverse events were similar as in the initial trial with higher rates of hypoglycemia in empagliflozin vs placebo (19.4\%-23.7\% vs $15.6 \%$ ), similar reports of UTI among all groups, and higher rates of genital infection in empagliflozin vs placebo $(4.5 \%-6.0 \%$ vs $0.9 \%)$.

Empagliflozin $10 \mathrm{mg} / \mathrm{d}$ or $25 \mathrm{mg} / \mathrm{d}$ as add-on therapy to metformin \pm pioglitazone also lowered $\mathrm{HbA} 1 \mathrm{c}(-0.6 \%$ and $-0.7 \%$ for empagliflozin $10 \mathrm{mg} / \mathrm{d}$ and $25 \mathrm{mg} / \mathrm{d}$, respectively, and $-0.1 \%$ for placebo) and body weight $(-1.62 \mathrm{~kg}$ and $-1.47 \mathrm{~kg}$ for empagliflozin $10 \mathrm{mg} / \mathrm{d}$ and $25 \mathrm{mg} / \mathrm{d}$, respectively, and $0.34 \mathrm{~kg}$ for placebo) at the end of 24 weeks compared with baseline. ${ }^{41}$ Out of 499 subjects enrolled, 75.5\% were on pioglitazone and metformin, while the remaining $24.5 \%$ were on pioglitazone alone. Both subsets of patients had similar reductions in HbA1c. Significant changes in FPG (+6.5 mg/dL for placebo and $-16.9 \mathrm{mg} / \mathrm{dL}$ and $-22.0 \mathrm{mg} / \mathrm{dL}$ for10 $\mathrm{mg} / \mathrm{d}$ and $25 \mathrm{mg} / \mathrm{d}$ of empagliflozin, respectively), waist circumference $(+0.20 \mathrm{~cm}$ for placebo and $-1.67 \mathrm{~cm}$ and $-0.92 \mathrm{~cm}$ for $10 \mathrm{mg} / \mathrm{d}$ and $25 \mathrm{mg} / \mathrm{d}$ of empagliflozin, respectively), systolic blood pressure $(+0.7 \mathrm{mmHg}$ for 
placebo and $-3.1 \mathrm{mmHg}$ and $-4.0 \mathrm{mmHg}$ for $10 \mathrm{mg} / \mathrm{d}$ and $25 \mathrm{mg} / \mathrm{d}$ of empagliflozin, respectively), and diastolic blood pressure $(+0.3 \mathrm{mmHg}$ for placebo and $-1.5 \mathrm{mmHg}$ and $-2.2 \mathrm{mmHg}$ for $10 \mathrm{mg} / \mathrm{d}$ and $25 \mathrm{mg} / \mathrm{d}$ of empagliflozin, respectively) were also observed. Adverse event rates were similar in all groups, with no increase in reported UTIs with empagliflozin (in fact, lower proportion of reports in empagliflozin $25 \mathrm{mg}$ group), but rates of genital infection (more common in women) were higher in empagliflozintreated individuals $(2.4 \%$ for placebo and $8.5 \%$ and $3.6 \%$ for $10 \mathrm{mg} / \mathrm{d}$ and $25 \mathrm{mg} / \mathrm{d}$ of empagliflozin, respectively). Confirmed hypoglycemia rates were similar and low in all groups $(1.2 \%-2.4 \%)$. No increases in edema or heart failure were reported in empagliflozin patients with background pioglitazone therapy. Bone fractures were reported in four patients receiving placebo and three patients in empagliflozin arms. Again, small increases in hematocrit and decreases in uric acid were observed. HDL increased slightly, but no other significant changes in lipids were demonstrated. This study shows that empagliflozin may successfully mitigate the effects of weight gain caused by pioglitazone and may help improve side effects such as edema.

One of the unexpected findings with SGLT2 inhibitor use was an increase in endogenous glucose production, in part due to increases in glucagon. ${ }^{42}$ Combining SGLT2 inhibitors with a glucagon-reducing agent like DPP4 inhibitors or glucagon-like peptide-1 agonists could thus provide an interesting synergy in enhancing glycemic control. No clinically meaningful PK differences are observed with coadministration of empagliflozin and the DPP4 inhibitor linagliptin. ${ }^{43}$ Empagliflozin and linagliptin have been studied as add-on to drug naïve and metformin-treated individuals to evaluate this synergy. ${ }^{44,45}$ In subjects not receiving treatment for T2DM for $\geq 12$ weeks, 677 individuals were randomized to either empagliflozin $25 \mathrm{mg}+$ linagliptin $5 \mathrm{mg}$ daily, empagliflozin $10 \mathrm{mg}+$ linagliptin $5 \mathrm{mg}$ daily, empagliflozin $25 \mathrm{mg}$ daily, empagliflozin $10 \mathrm{mg}$ daily, and linagliptin $5 \mathrm{mg}$ daily. ${ }^{44}$ Improvements in HbA1c from baseline were demonstrated after 24 weeks of therapy in all groups $(-1.08 \%,-1.24 \%,-0.95 \%,-0.83 \%$, and $-0.67 \%$ for empagliflozin $25 \mathrm{mg}+$ linagliptin $5 \mathrm{mg}$ daily, empagliflozin $10 \mathrm{mg}$ + linagliptin $5 \mathrm{mg}$ daily, empagliflozin $25 \mathrm{mg}$ daily, empagliflozin $10 \mathrm{mg}$ daily, and linagliptin $5 \mathrm{mg}$ daily, respectively). However, in the empagliflozin $25 \mathrm{mg}+$ linagliptin $5 \mathrm{mg}$ vs empagliflozin $25 \mathrm{mg}$, the changes in HbA1c were not significant. Subjects with higher baseline HbA1c $(\geq 8.5 \%$ ) at study entry had more pronounced improvements in $\mathrm{HbA} 1 \mathrm{c}$ at 24 weeks with combination therapy $(-1.62 \%$ to
$-1.63 \%$ ) vs empagliflozin monotherapy ( $-1.66 \%$ to $-1.54 \%)$ or linagliptin monotherapy $(-1.07 \%)$. Again changes were not significant in the empagliflozin $25 \mathrm{mg}$ combination vs monotherapy arms. A significantly higher number of individuals with baseline $\mathrm{HbA} 1 \mathrm{c} \geq 7 \%$ achieved $\mathrm{HbA} 1 \mathrm{c}<7 \%$ at the end of 24 weeks in the combination groups (55.4\%-62.3\%) vs those with monotherapies $(32.3 \%-41.5 \%)$. Combination therapy also led to greater weight loss $(2.0-2.7 \mathrm{~kg})$ and FPG $(-28.21 \mathrm{mg} / \mathrm{dL}$ to $-29.55 \mathrm{mg} / \mathrm{dL})$ vs linagliptin $(-0.8 \mathrm{~kg}$ and $-5.92 \mathrm{~mm} / \mathrm{dL}$, respectively) but not when compared with empagliflozin monotherapies. Changes in $\mathrm{HbA} 1 \mathrm{c}$ were maintained at 52 weeks $(-1.17 \%$ to $-1.22 \%$ in combination groups, $-1.01 \%$ to $-0.85 \%$ in empagliflozin monotherapy groups, and $-0.51 \%$ in the linagliptin group), with the empagliflozin $25 \mathrm{mg}$ groups again not showing significant differences. Body weight and FPG changes at 52 weeks were only significant with combination therapy when compared to linagliptin and not empagliflozin monotherapy. In all, $>50 \%$ of subjects on combination treatment with baseline $\mathrm{HbA} 1 \mathrm{c} \geq 7 \%$ were able to maintain $\mathrm{HbA} 1 \mathrm{c}<7 \%$ at the end of 52 weeks. Blood pressure did not differ significantly with combination therapy vs empagliflozin monotherapy. There were no confirmed hypoglycemic adverse events with combination therapy. UTIs were reported in $10.4 \%$ of linagliptin-treated patients vs $10.4 \%-16.3 \%$ in empagliflozin groups, and genital infections were more common overall in empagliflozin groups $(2.9 \%-5.9 \%)$ vs linagliptin $(3.0 \%)$. No patients experienced heart failure exacerbations, and again, there were mild increases in hematocrit and decreases in uric acid, but no significant changes in lipids among the empagliflozin groups.

Similarly, empagliflozin and linagliptin combination therapy compared with individual therapies (empagliflozin $25 \mathrm{mg}+$ linagliptin $5 \mathrm{mg}$ daily, empagliflozin $10 \mathrm{mg}+$ linagliptin $5 \mathrm{mg}$ daily, empagliflozin $25 \mathrm{mg}$ daily, empagliflozin $10 \mathrm{mg}$ daily, and linagliptin $5 \mathrm{mg}$ daily) as add-on to preexisting metformin also showed improvements in $\mathrm{HbA} 1 \mathrm{c}$ at 24 weeks $(-1.08 \%$ to $-1.19 \%$ with combination therapy vs $-0.62 \%$ to $-0.70 \%$ with individual therapies), which were sustained for 52 weeks. ${ }^{45}$ A significant proportion of patients on combination therapy achieved a HbA1c $\leq 7 \%$ at the end of 24 weeks vs monotherapies ( $~ 60 \%$ vs $\sim 30 \%-35 \%)$ and again at 52 weeks ( $\sim 50 \%$ vs $\sim 30 \%)$. FPG improved at 24 weeks with combination therapy compared to monotherapies $(-32.2 \mathrm{mg} / \mathrm{dL}$ to $-35.3 \mathrm{mg} / \mathrm{dL}$ vs $-13.1 \mathrm{mg} / \mathrm{dL}$ to $-20.8 \mathrm{mg} / \mathrm{dL}$ ), but body weight was decreased in all empagliflozin arms $(-2.5 \mathrm{~kg}$ to $-3.2 \mathrm{~kg})$ vs those with linagliptin therapy $(-0.7 \mathrm{~kg})$ at 24 weeks and at 52 weeks $(-2.7 \mathrm{~kg}$ to 
$-3.1 \mathrm{~kg}$ vs $-0.3 \mathrm{~kg}$, respectively). Blood pressure did not differ significantly among empagliflozin-treated groups. Rates of hypoglycemia were low in all groups $(1.4 \%-3.6 \%)$ and not severe. UTIs were reported in a higher proportion of linagliptin monotherapy-treated individuals compared with combination or empagliflozin monotherapy, and genital infections were higher overall in empagliflozin-treated subjects $(2.2 \%-8.5 \%)$ vs those with linagliptin monotherapy (2.3\%). There were no reports of heart failure exacerbation. A greater proportion of patients with albuminuria at baseline reverted to no albuminuria at the study end with combination therapy vs individual treatments. Hematocrit, uric acid, and lipid changes were consistent with prior studies.

The combination of empagliflozin and linagliptin unfortunately did not provide an additive synergistic effect, and in fact, many of the end points with combination therapy were similar to those achieved with empagliflozin monotherapy. However, the combination does provide an alternative to other oral agents \pm basal insulin for those patients needing additional and sustainable improvements in HbA1c.

A trial to evaluate whether empagliflozin given $12.5 \mathrm{mg}$ bid, $25 \mathrm{mg}$ daily, $5 \mathrm{mg}$ bid, or $10 \mathrm{mg}$ daily vs placebo as add-on to metformin demonstrated that at 16 weeks, once daily empagliflozin was noninferior to twice daily empagliflozin and vice versa. ${ }^{46}$ Thus, there is no reason to consider multiple daily dosing regimens with empagliflozin.

\section{Add-on to insulin}

Since empagliflozin has a mechanism of action that is primarily insulin independent, it may have utility in patients across a wide spectrum of T2DM. When added to basal insulin with or without metformin and/or SU in 494 patients with T2DM, empagliflozin $10 \mathrm{mg} / \mathrm{d}$ and $25 \mathrm{mg} / \mathrm{d}$ showed reductions in $\mathrm{HbA} 1 \mathrm{c}$ ( $0.0 \%$ for placebo and $-0.5 \%$ and $-0.6 \%$ for $10 \mathrm{mg} / \mathrm{d}$ and $25 \mathrm{mg} / \mathrm{d}$ of empagliflozin, respectively), body weight ( $+0.7 \mathrm{~kg}$ for placebo and $-2.2 \mathrm{~kg}$ and $-2.0 \mathrm{~kg}$ for $10 \mathrm{mg} / \mathrm{d}$ and $25 \mathrm{mg} / \mathrm{d}$ of empagliflozin, respectively), and insulin dose (+5.5 units/d for placebo and -1.2 units/d and $-0.5 \mathrm{units} / \mathrm{d}$ for $10 \mathrm{mg} / \mathrm{d}$ and $25 \mathrm{mg} / \mathrm{d}$ of empagliflozin, respectively) vs placebo at the end of 78 weeks of treatment. ${ }^{47}$ FPG also improved by $12.6-18.0 \mathrm{mg} / \mathrm{dL}$ in empagliflozintreated individuals vs placebo. Changes in blood pressure were small and significant in empagliflozin $10 \mathrm{mg} / \mathrm{d}$ subjects but did not reach statistical significance at 78 weeks in the empagliflozin $25 \mathrm{mg} / \mathrm{d}$ group. Adverse event rates were similar across treatment arms, and no significant difference was seen in hypoglycemia in empagliflozin- vs placebo-treated subjects. UTIs were more common in empagliflozin-treated individuals ( $9 \%$ vs $12 \%-15 \%$ ) as were genital infections ( $2 \%$ vs $5 \%-8 \%$ ). No significant changes in lipids, small increases in hematocrit, and small decreases in uric acid levels were observed.

Furthermore, individuals at an even more advanced stage of T2DM on multiple daily injections of insulin (baseline total daily insulin was 92 units/d) \pm metformin treated with empagliflozin $10 \mathrm{mg} / \mathrm{d}$ or $25 \mathrm{mg} / \mathrm{d}$ or placebo showed reductions in $\mathrm{HbA} 1 \mathrm{c}$ at the end of 18 weeks $(-0.50 \%$ for placebo and $-0.94 \%$ and $-1.02 \%$ for $10 \mathrm{mg} / \mathrm{d}$ and $25 \mathrm{mg} / \mathrm{d}$ of empagliflozin, respectively) and 52 weeks $(-0.81 \%$ for placebo and $-1.18 \%$ and $-1.27 \%$ for $10 \mathrm{mg} / \mathrm{d}$ and $25 \mathrm{mg} / \mathrm{d}$ of empagliflozin, respectively). ${ }^{48}$ Decreases in total daily insulin dose (-9 units/d to -11 units/d) and body weight $(-2.4 \mathrm{~kg}$ to $-2.5 \mathrm{~kg})$ were also apparent in empagliflozintreated subjects vs placebo at the end of 52 weeks. FPG improved by $-11.3 \mathrm{mg} / \mathrm{dL}$ in the placebo arm vs $-23.8 \mathrm{mg} / \mathrm{dL}$ to $-25.8 \mathrm{mg} / \mathrm{dL}$ in empagliflozin-treated participants at the end of 52 weeks. Confirmed hypoglycemia rates were slightly higher in empagliflozin-treated patients $(39.8 \%-41.3 \%)$ vs placebo (37.2\%) at the end of 18 weeks but not significantly different at the end of 52 weeks with only four cases of severe hypoglycemia in empagliflozin-treated subjects vs three cases in the placebo group. Rates of UTI were again not different among the treatment arms, but genital infections were once again reported in higher proportions of patients treated with empagliflozin vs placebo $(4.3 \%-9.5 \%$ vs $1.6 \%)$. No significant changes in lipids, small increases in hematocrit, and a small decline in uric acid levels were all observed in empagliflozin-treated individuals.

\section{Cardiovascular outcomes}

It has been well established that strict glycemic control decreases microvascular tissue complications of diabetes, but the effects of rigorous glycemic control on macrovascular outcomes have been less clearly established. Longer term follow-up may unveil, ${ }^{49,50}$ and specific agents may confer greater cardiovascular benefits than others. ${ }^{51-53}$ Potential cardiovascular benefits are seen with empagliflozin in lowering blood pressure, arterial stiffness, and vascular resistance.$^{54,55} \mathrm{~A}$ robust multinational, clinical trial (EMPAREG OUTCOME) examining the effects of empagliflozin $10 \mathrm{mg} / \mathrm{d}$ or $25 \mathrm{mg} / \mathrm{d}$ (either monotherapy or as add-on to stable existing therapy) vs placebo on cardiovascular morbidity and mortality in high-risk patients with T2DM ( $>99 \%$ of patients had established cardiovascular disease) enrolled 7,028 subjects treated for a median duration of 2.6 years and a median observation period of 3.1 years. ${ }^{56}$ 
The primary outcome, a composite of death from cardiovascular causes, nonfatal myocardial infarction, or nonfatal stroke, occurred in a significantly lower percentage of patients in the pooled empagliflozin group than placebo (10.5\% vs 12.1\%; hazard ratio [HR] 0.86). Compared with placebo, empagliflozin significantly lowered the risk of death from cardiovascular causes (HR 0.62), death from any cause (HR 0.68 ), and hospitalization for heart failure (HR 0.65). At 12 weeks, the difference in $\mathrm{HbA} 1 \mathrm{c}$ was $-0.54 \%$ to $-0.60 \%$ in the empagliflozin group vs placebo; at week 94 , the difference was $-0.42 \%$ to $-0.47 \%$; and at week 206 , the difference decreased to $-0.24 \%$ to $-0.36 \%$. Interestingly, subgroup analyses showed greater reduction in the primary end point and cardiovascular death in individuals $\geq 65$ years of age and in those individuals with glycated hemoglobin $<8.5 \%$. Small decreases in body weight, waist circumference, uric acid, and blood pressure were noted in subjects treated with empagliflozin, with small increases in LDL and HDL cholesterol levels. Confirmed hypoglycemia and overall rates of UTI did not differ between groups, but genital infections were higher with empagliflozin therapy. DKA was rarely reported, with one patient in the placebo group and four patients in the pooled empagliflozin group.

The dramatic reduction in all-cause and cardiovascular mortality combined with the reduction in hospitalization for heart failure with empagliflozin treatment is an appealing finding. Heart failure is a known complication of diabetes, which often goes unnoticed, ${ }^{57,58}$ but has surfaced more recently as a potential complication of diabetes treatments such as DPP4 inhibitor therapy ${ }^{59}$ and is strongly associated with thiazolidinedione use. ${ }^{60}$ Patients with diabetes are $\sim 2.5$ times more likely to develop congestive heart failure than those without diabetes. ${ }^{58}$ Therefore, an agent that may significantly reduce rates of hospitalization due to heart failure in patients with diabetes is a welcome addition to the therapeutic treatment options for T2DM.

The cardiovascular benefits of empagliflozin over a short duration while intriguing deserve further study. Along with reductions in blood pressure, waist circumference, and body weight, consistent reductions in uric acid were observed in most trials. Improvements in arterial stiffness, insulin sensitivity, visceral adiposity, and oxidative stress may all contribute to the cardiovascular benefits of empagliflozin. ${ }^{61}$ Changes in uric acid are likely due to GLUT9, expressed in both apical and basolateral membranes of proximal renal tubular cells, which transport urate back into urine in exchange for glucose. ${ }^{62}$ Uric acid may be a causative factor rather than just a marker of cardiovascular disease. ${ }^{63}$
Interestingly, lowering uric acid levels may also decrease the propensity for progression of renal disease. ${ }^{64}$ It has also been demonstrated that much of the weight loss with empagliflozin therapy as assessed by magnetic resonance imaging is due to a reduction in visceral fat mass. ${ }^{38}$ The decrease in heart failure hospitalizations may in part be due to empagliflozin's diuretic effect and mild volume depletion as evidenced by small increases in hematocrit.

\section{Renal disease}

To specifically evaluate the safety and efficacy of empagliflozin in patients with T2DM and chronic kidney disease (CKD), in a Phase III multinational trial, 664 individuals with either stage $2\left(\mathrm{eGFR} \geq 60 \mathrm{~mL} / \mathrm{min} / 1.73 \mathrm{~m}^{2}\right.$ and $<90 \mathrm{~mL} /$ $\left.\mathrm{min} / 1.73 \mathrm{~m}^{2}\right)$ or stage $3\left(\mathrm{eGFR} \geq 30 \mathrm{~mL} / \mathrm{min} / 1.73 \mathrm{~m}^{2}\right.$ and $<60 \mathrm{~mL} / \mathrm{min} / 1.73 \mathrm{~m}^{2}$ ) CKD were randomly assigned to either empagliflozin or placebo. ${ }^{65}$ Patients with stage 2 CKD received either placebo, $10 \mathrm{mg} / \mathrm{d}$ or $25 \mathrm{mg} / \mathrm{d}$ of empagliflozin, whereas patients with stage $3 \mathrm{CKD}$ received only empagliflozin $25 \mathrm{mg} / \mathrm{d}$ or placebo. Significant changes from baseline in $\mathrm{HbA} 1 \mathrm{c}$ at the end of 24 weeks were $-0.46 \%$ in empagliflozin $10 \mathrm{mg} / \mathrm{d}$ and $-0.63 \%$ in empagliflozin $25 \mathrm{mg} / \mathrm{d}$ patients with stage $2 \mathrm{CKD}$ (vs placebo $+0.06 \%$ ). In patients with stage $3 \mathrm{CKD}$, a $-0.37 \%$ reduction in $\mathrm{HbA} 1 \mathrm{c}$ at the end of 24 weeks was significant compared to a $0.05 \%$ increase in the placebo arm. HbA1c changes were sustained at 52 weeks in patients both with stage 2 and stage 3 CKD. Significant reductions in body weight $(-1.76 \mathrm{~kg}$ to $-2.33 \mathrm{~kg})$, systolic blood pressure $(-2.9 \mathrm{mmHg}$ to $-4.5 \mathrm{mmHg})$, and diastolic blood pressure $(-1.4 \mathrm{mmHg}$ to $-2.2 \mathrm{mmHg})$ were also demonstrated in patients with stage $2 \mathrm{CKD}$ treated with empagliflozin at 24 weeks compared with baseline, and these reductions were maintained over 52 weeks. Similarly in patients with stage 3 CKD treated with empagliflozin $25 \mathrm{mg} / \mathrm{d}$, significant improvements in body weight $(-0.98 \mathrm{~kg})$, systolic blood pressure $(-3.9 \mathrm{mmHg})$, and diastolic blood pressure $(-1.7 \mathrm{mmHg})$ were seen at 24 weeks and maintained over 52 weeks. An exploratory arm of the study evaluating patients with stage 4 CKD receiving empagliflozin $25 \mathrm{mg} / \mathrm{d}$ did not show improvements in HbA1c at week 24 or 52. However, reductions in body weight $(\sim 1 \mathrm{~kg})$, systolic blood pressure $(-7.4 \mathrm{mmHg}$ to $-11.2 \mathrm{mmHg})$, and diastolic blood pressure $(-2.4 \mathrm{mmHg}$ to $-4.3 \mathrm{mmHg})$ were still seen at 24 weeks and 52 weeks. Hypoglycemia was reported in a similar proportion of subjects treated with placebo or empagliflozin at all stages of CKD. Rates of UTIs and genital infections were also similar in patients with stage $2 \mathrm{CKD}$ treated with empagliflozin vs placebo. In patients with stage $3 \mathrm{CKD}$, rates of UTIs did 
not differ; however, genital infections were more common in patients treated with empagliflozin, although absolute number of infections was small $(n=7)$. Small decreases in eGFR were noted in all groups treated with empagliflozin; however, improvements in urine albumin to creatinine ratios were demonstrated at week 52 in both stage 2 and 3 CKD patients.

Preliminary renal outcomes from the EMPA-REG OUTCOME trial showed that individuals treated with empagliflozin had a $39 \%$ reduction in new onset or worsening of nephropathy (HR 0.61). ${ }^{66}$ Significant reductions in the composite outcome of doubling of serum creatinine, initiation of renal replacement therapy, or death due to renal disease were also seen with empagliflozin treatment (HR 0.54). Patients with CKD (eGFR $<60 \mathrm{~mL} / \mathrm{min} / 1.73 \mathrm{~m}^{2}$ ) receiving empagliflozin still benefited from significant reductions in the primary composite cardiovascular end point and cardiac death.

\section{Comparative safety, efficacy, and tolerability of empagliflozin in T2DM}

Abundant clinical data now exist regarding treatment of T2DM with empagliflozin as being safe, efficacious, and generally well tolerated by patients. HbA1c lowering is generally $-0.6 \%$ to $-0.9 \%$ as monotherapy or add-on therapy to existing oral agents or insulin. Glycemic lowering is even more pronounced in patients with double-digit $\mathrm{HbA} 1 \mathrm{c}$, where reductions of $\sim 3 \%$ can be observed. A distinct advantage of SGLT2 inhibition is the ability to lower glucose in a wide range of patients from those who are drug naïve to individuals on multiple daily injections of insulin. Data show that empagliflozin can even result in significant lowering of $\mathrm{HbAlc}$ in patients with stage 2 or stage $3 \mathrm{CKD}$, albeit to a lesser degree than those with normal renal function. However, lowering of 24-hour systolic blood pressure may occur to an even greater degree in patients with CKD, indicating a nonglucosuric effect on blood pressure. ${ }^{67}$ With nonglycemic benefits, such as weight loss and lowering of blood pressure, empagliflozin can target the multiple deleterious comorbidities in patients with diabetes without an increase in the primary feared risk of diabetes therapy hypoglycemia. More recently, we have observed that these multifaceted benefits translate into significant and rapid cardiovascular risk reduction in patients treated with empagliflozin, as well as decreases in adverse renal outcomes. Definitive improvements in both macrovascular and microvascular outcomes with a single diabetes therapy are unprecedented, offering a promising treatment option for a wide range of patients with T2DM (Figure 1 and Table 2).

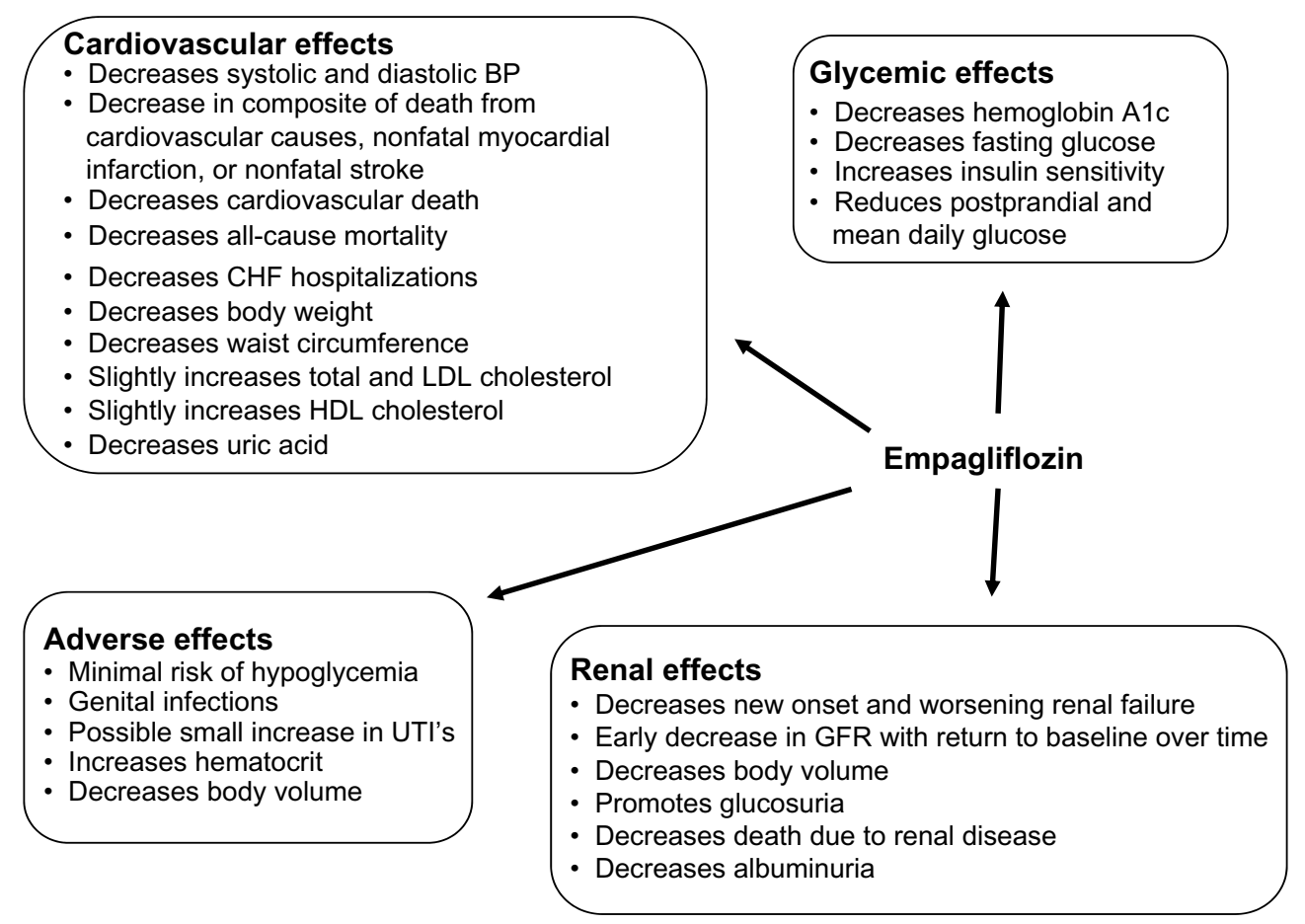

Figure I A summary of the glycemic, cardiovascular, renal, and adverse effects of empagliflozin.

Abbreviations: GFR, glomerular filtration rate; HDL, high-density lipoprotein; LDL, low-density lipoprotein; UTI, urinary tract infection; BP, blood pressure; CHF, congestive heart failure. 
Table 2 Clinical properties of empagliflozin when given orally at clinically available doses of either $10 \mathrm{mg} / \mathrm{d}$ or $25 \mathrm{mg} / \mathrm{d}$

\begin{tabular}{ll}
\hline Clinical properties of empagliflozin (10-25 mg/d) \\
\hline Decrease in HbAlc & $\sim-0.6 \%-0.9 \%$ \\
Decrease in fasting plasma glucose & $\sim-20 \mathrm{mg} / \mathrm{dL}$ to \\
& $-35 \mathrm{mg} / \mathrm{dL}$ \\
Decrease in HbAIc with baseline Alc $\geq 8.5 \%$ & $\sim 1.2 \%-1.4 \%$ \\
Decrease in HbAIc with baseline AIc $\geq 10 \%$ & $\sim 3 \%$ \\
Decrease in HbAIc with stage 2 or 3 CKD & $\sim-0.4 \%$ to $-0.6 \%$ \\
Decrease in body weight & $\sim 2-3 \mathrm{~kg}$ \\
Decrease in fasting plasma glucose & $\sim 20-30 \mathrm{mg} / \mathrm{dL}$ \\
Decrease in systolic blood pressure & $\sim 3-7 \mathrm{mmHg}$ \\
Decrease in diastolic blood pressure & $\sim 1-3 \mathrm{mmHg}$ \\
Decrease in waist circumference & $\sim 1-1.5 \mathrm{~cm}$ \\
Decrease in uric acid & $\sim 0.5-1 \mathrm{mg} / \mathrm{dL}$ \\
Decreased risk of death from cardiovascular cause & $-38 \%$ \\
Decreased all-cause mortality & $-32 \%$ \\
Decreased hospitalization for congestive heart failure & $-35 \%$ \\
Decreased new onset or worsening of neuropathy & $-39 \%$ \\
Hypoglycemia & $\sim 3 \%-5 \%$ \\
Genital infections & $\sim 3 \%-5 \%$ \\
\hline
\end{tabular}

Abbreviations: $\mathrm{HbAIc}$, hemoglobin Alc; CKD, chronic kidney disease.

Although no direct clinical comparisons exist among the available SGLT2 inhibitors, studies show similar degrees of reduction in $\mathrm{HbA1c}$, body weight, FPG, and blood pressure with dapagliflozin, canagliflozin, and empagliflozin. ${ }^{68}$ Empagliflozin has higher selectivity for SGLT2 than either dapagliflozin or canagliflozin. Both canagliflozin and empagliflozin are approved for use in patients with eGFR down to $45 \mathrm{~mL} / \mathrm{min} / 1.73 \mathrm{~m}^{2}$. However, dapagliflozin approval is only for patients with eGFR $>60 \mathrm{~mL} / \mathrm{min} / 1.73 \mathrm{~m}^{2}$. Currently, cardiovascular outcomes data only exist for empagliflozin; however, studies evaluating outcomes for both canagliflozin and dapagliflozin are underway.

There are limited head-to-head data comparing empagliflozin with other drug classes used to treat T2DM. When compared to sitagliptin and metformin, empagliflozin therapy resulted in similar reductions in $\mathrm{HbAl} \mathrm{c}$ but greater improvements in fasting blood glucose compared with sitagliptin and greater reductions in body weight compared with both metformin and sitagliptin. ${ }^{26,35}$

In a noninferiority trial comparing empagliflozin to glimepiride, empagliflozin demonstrated a $-0.11 \%$ lower $\mathrm{HbA1c}$ at 104 weeks, which was significantly superior to glimepiride treatment $(P=0.0153) \cdot{ }^{38} \mathrm{FPG}(-3.06 \mathrm{mg} / \mathrm{dL}$ vs $-15.3 \mathrm{mg} / \mathrm{dL}$ for glimepiride vs empagliflozin, respectively) and body weight (difference $-4.61 \mathrm{~kg}$ ) were also lower compared to baseline with add-on empagliflozin vs glimepiride. Systolic blood pressure and diastolic blood pressure were lower at 2 years with empagliflozin compared with glimepiride. This study also showed that $\sim 90 \%$ of the weight loss with empagliflozin was mainly due to a reduction in abdominal fat mass. Both dapagliflozin and canagliflozin have shown similar effects on body composition. ${ }^{69,70}$

Among all the empagliflozin studies, there is little difference in $\mathrm{HbA} 1 \mathrm{c}$ reduction or change in body weight when comparing $10 \mathrm{mg} / \mathrm{d}$ vs $25 \mathrm{mg} / \mathrm{d}$. Empagliflozin $25 \mathrm{mg} / \mathrm{d}$ does seem to provide greater reductions in blood pressure though.

Empagliflozin was well tolerated in clinical trials with very low rates of dropout. The only consistent adverse effect with empagliflozin therapy reported in greater proportion of patients than placebo was genital infection. DKA has recently become a concern for patients treated with SGLT2 inhibitors. ${ }^{71}$ However, the rates of DKA were very low in all reported data for patients with T2DM. One study did report higher levels of ketone bodies in individuals with T2DM treated with empagliflozin ${ }^{31}$ but not to the levels that typically accompany DKA. SGLT2 inhibitors used in patients with type 1 diabetes most likely pose a higher risk of DKA, and patients treated off-label for type 1 diabetes need to be monitored closely. Bone fractures are another recent concern as a possible adverse effect from using SGLT2 inhibitors. ${ }^{72}$ Most trials utilizing empagliflozin, however, did not report on fractures or rates were very low to draw conclusions. The side effect profile of empagliflozin is very similar to other SLGT2 inhibitors. Higher rates of genital infections are seen with SGLT2 inhibitors vs other classes of medications for T2DM.

\section{Conclusion}

Empagliflozin is a highly selective SGLT2 inhibitor with higher selectivity for SGLT2 than other comparable agents currently on the market. Empagliflozin taken orally reaches maximal concentration in 1.5-2 hours, with a terminal elimination half-life of $\sim 8-14$ hours and can be taken with or without food. Empagliflozin causes a consistent glucosuria of $\sim 40-90 \mathrm{~g} / \mathrm{d}$. When used as monotherapy, add-on to metformin or other oral agents, add-on to insulin, or in combination with the DPP4 inhibitor linagliptin, empagliflozin shows consistent reduction in HbA1c, FPG levels, and body weight. Classic therapies for T2DM such as insulin and SU are plagued by the adverse events of weight gain and hypoglycemia. Empagliflozin, in contrast, offers the potential for weight loss without a significant increase in risk of hypoglycemia. Reductions in both systolic blood pressure of $\sim 3-7 \mathrm{mmHg}$ and diastolic blood pressure 
of $\sim 1-3 \mathrm{mmHg}$ are also seen with empagliflozin treatment in patients with T2DM with or without hypertension. In fact, most probably, the glycemic and nonglycemic benefits combine to allow a reduction in cardiovascular death, renal dysfunction, and congestive heart failure. The dramatic improvements in $\mathrm{HbAlc}$ with empagliflozin use in patients with $\mathrm{HbA} 1 \mathrm{c}>10 \%$ or when used in combination with linagliptin also provide oral options for patients who need rapid reductions in glucose with uncontrolled T2DM without significantly increasing hypoglycemic risk.

Although treatment with empagliflozin results in a temporary decrease in eGFR, this usually reverts back to baseline with over time. Also, reversion of albuminuria in patients with T2DM can occur with empagliflozin use. ${ }^{45,65}$ In a small study of patients with type 1 diabetes, empagliflozin attenuated hyperfiltration, ${ }^{73}$ and in preclinical studies, it reduced markers of renal inflammation and fibrosis. ${ }^{74,75}$ The only large outcomes trial to evaluate empagliflozin effects on renal outcomes shows very promising preliminary data, showing a significant decrease in new onset and worsening nephropathy and maintaining cardiovascular benefits in patients with CKD.

Tolerability for empagliflozin is excellent with no significant increase in hypoglycemia and genital infections being the only consistent adverse event reported in higher proportions with treatment. Whether the cardiovascular and renal outcome benefits are unique to empagliflozin or an SGLT2 inhibitor class effect remains to be elucidated. Overall, empagliflozin provides a reasonable alternative for many patients across the T2DM spectrum, providing both glycemic and nonglycemic benefits, which lead to significant and rapid reductions in both micro- and macrovascular outcomes.

\section{Disclosure}

The authors report no conflicts of interest in this work.

\section{References}

1. Diabetes Programme [webpage on the Internet]. World Health Organization Diabetes Programme. Available from: http://www.who.int/diabetes/ en/. Accessed December 1, 2015.

2. Inzucchi SE, Bergenstal RM, Buse JB, et al; American Diabetes Association (ADA); European Association for the Study of Diabetes (EASD). Management of hyperglycemia in type 2 diabetes: a patient-centered approach: position statement of the American Diabetes Association (ADA) and the European Association for the Study of Diabetes (EASD). Diabetes Care. 2012;35(6):1364-1379.

3. Emerging Risk Factors Collaboration, Sarwar N, Gao P, et al. Diabetes mellitus, fasting blood glucose concentration, and risk of vascular disease: a collaborative meta-analysis of 102 prospective studies. Lancet. 2010;375(9733):2215-2222.
4. Emerging Risk Factors Collaboration, Di Angelantonio E, Kaptoge S, et al. Association of cardiometabolic multimorbidity with mortality. JAMA. 2015;314(1):52-60.

5. FDA [webpage on the Internet]. FDA Approves Jardiance to Treat Type 2 Diabetes; 2014. Available from: http://www.fda.gov/ NewsEvents/Newsroom/PressAnnouncements/ucm407637.htm. Accessed December 15, 2015.

6. Abdul-Ghani MA, DeFronzo RA. Lowering plasma glucose concentration by inhibiting renal sodium-glucose cotransport. J Intern Med. 2014;276(4):352-363.

7. Wright EM, Hirayama BA, Loo DF. Active sugar transport in health and disease. J Intern Med. 2007;261(1):32-43.

8. Abdul-Ghani MA, DeFronzo RA, Norton L. Novel hypothesis to explain why SGLT2 inhibitors inhibit only $30-50 \%$ of filtered glucose load in humans. Diabetes. 2013;62(10):3324-3328.

9. Grempler R, Thomas L, Eckhardt M, et al. Empagliflozin, a novel selective sodium glucose cotransporter-2 (SGLT-2) inhibitor: characterisation and comparison with other SGLT-2 inhibitors. Diabetes Obes Metab. 2012;14(1):83-90.

10. Merovci A, Solis-Herrera C, Daniele G, et al. Dapagliflozin improves muscle insulin sensitivity but enhances endogenous glucose production. J Clin Invest. 2014;124(2):509-514.

11. Scheen AJ. Pharmacokinetic and pharmacodynamic profile of empagliflozin, a sodium glucose co-transporter 2 inhibitor. Clin Pharmacokinet. 2014;53(3):213-225.

12. Seman L, Macha S, Nehmiz G, et al. Empagliflozin (BI 10773), a potent and selective SGLT2 inhibitor, induces dose-dependent glucosuria in healthy subjects. Clin Pharm Drug Dev. 2013;2(2):152-161.

13. Macha S, Jungnik A, Hohl K, Hobson D, Salsali A, Woerle HJ. Effect of food on the pharmacokinetics of empagliflozin, a sodium glucose cotransporter 2 (SGLT2) inhibitor, and assessment of dose proportionality in healthy volunteers. Int J Clin Pharmacol Ther. 2013;51(11):873-879.

14. Sarashina A, Koiwai K, Seman LJ, et al. Safety, tolerability, pharmacokinetics and pharmacodynamics of single doses of empagliflozin, a sodium glucose cotransporter 2 (SGLT2) inhibitor, in healthy Japanese subjects. Drug Metab Pharmacokinet. 2013;28(3):213-219.

15. Heise T, Seewaldt-Becker E, Macha S, et al. Safety, tolerability, pharmacokinetics and pharmacodynamics following 4 weeks' treatment with empagliflozin once daily in patients with type 2 diabetes. Diabetes Obes Metab. 2013;15(7):613-621.

16. Heise T, Seman L, Macha S, et al. Safety, tolerability, pharmacokinetics, and pharmacodynamics of multiple rising doses of empagliflozin in patients with type 2 diabetes mellitus. Diabetes Ther. 2013;4(2):331-345.

17. Kanada S, Koiwai K, Taniguchi A, Sarashina A, Seman L, Woerle HJ. Pharmacokinetics, pharmacodynamics, safety and tolerability of 4 weeks' treatment with empagliflozin in Japanese patients with type 2 diabetes mellitus. J Diabetes Investig. 2013;4(6):613-617.

18. Coll-de-Tuero G, Mata-Cases M, Rodriguez-Poncelas A, et al. Chronic kidney disease in the type 2 diabetic patients: prevalence and associated variables in a random sample of 2642 patients of a Mediterranean area. BMC Nephrol. 2012;13:87.

19. Macha S, Mattheus M, Halabi A, Pinnetti S, Woerle HJ, Broedl UC. Pharmacokinetics, pharmacodynamics and safety of empagliflozin, a sodium glucose cotransporter 2 (SGLT2) inhibitor, in subjects with renal impairment. Diabetes Obes Metab. 2014;16(3): 215-222.

20. Sarashina A, Ueki K, Sasaki T, et al. Effect of renal impairment on the pharmacokinetics, pharmacodynamics, and safety of empagliflozin, a sodium glucose cotransporter 2 inhibitor, in Japanese patients with type 2 diabetes mellitus. Clin Ther. 2014;36(11):1606-1615.

21. Macha S, Rose P, Mattheus M, et al. Pharmacokinetics, safety and tolerability of empagliflozin, a sodium glucose cotransporter 2 inhibitor, in patients with hepatic impairment. Diabetes Obes Metab. 2014;16(2):118-123. 
22. Riggs MM, Staab A, Seman L, et al. Population pharmacokinetics of empagliflozin, a sodium glucose cotransporter 2 inhibitor, in patients with type 2 diabetes. J Clin Pharmacol. 2013;53(10): 1028-1038.

23. Ferrannini E, Seman L, Seewaldt-Becker E, Hantel S, Pinnetti S, Woerle HJ. A phase IIb, randomized, placebo-controlled study of the SGLT2 inhibitor empagliflozin in patients with type 2 diabetes. Diabetes Obes Metab. 2013;15(8):721-728.

24. Kadowaki T, Haneda M, Inagaki N, et al. Empagliflozin monotherapy in Japanese patients with type 2 diabetes mellitus: a randomized, 12-week, double-blind, placebo-controlled, phase II trial. Adv Ther. 2014;31(6):621-638.

25. Kadowaki T, Haneda M, Inagaki N, et al. Efficacy and safety of empagliflozin monotherapy for 52 weeks in Japanese patients with type 2 diabetes: a randomized, double-blind, parallel-group study. Adv Ther. 2015;32(4):306-318

26. Roden M, Weng J, Eilbracht J, et al. Empagliflozin monotherapy with sitagliptin as an active comparator in patients with type 2 diabetes: a randomised, double-blind, placebo-controlled, phase 3 trial. Lancet Diabetes Endocrinol. 2013;1(3):208-219.

27. Tikkanen I, Narko K, Zeller C, et al. Empagliflozin reduces blood pressure in patients with type 2 diabetes and hypertension. Diabetes Care. 2015;38(3):420-428.

28. Cavalot F, Pagliarino A, Valle M, et al. Postprandial blood glucose predicts cardiovascular events and all-cause mortality in type 2 diabetes in a 14-year follow-up: lessons from the San Luigi Gonzaga Diabetes Study. Diabetes Care. 2011;34(10):2237-2243.

29. Cavalot F, Petrelli A, Traversa M, et al. Postprandial blood glucose is a stronger predictor of cardiovascular events than fasting blood glucose in type 2 diabetes mellitus, particularly in women: lessons from the San Luigi Gonzaga Diabetes Study. J Clin Endocrinol Metab. 2006;91(3):813-819.

30. Monnier L, Mas E, Ginet C, et al. Activation of oxidative stress by acute glucose fluctuations compared with sustained chronic hyperglycemia in patients with type 2 diabetes. JAMA. 2006;295(14):1681-1687.

31. Nishimura R, Tanaka Y, Koiwai K, et al. Effect of empagliflozin monotherapy on postprandial glucose and 24-hour glucose variability in Japanese patients with type 2 diabetes mellitus: a randomized, double-blind, placebo-controlled, 4-week study. Cardiovasc Diabetol. 2015;14:11.

32. Laffel L. Ketone bodies: a review of physiology, pathophysiology and application of monitoring to diabetes. Diabetes Metab Res Rev. 1999;15(6):412-426.

33. Araki E, Tanizawa Y, Tanaka Y, et al. Long-term treatment with empagliflozin as add-on to oral antidiabetes therapy in Japanese patients with type 2 diabetes mellitus. Diabetes Obes Metab. 2015;17(7): 665-674.

34. Rosenstock J, Seman LJ, Jelaska A, et al. Efficacy and safety of empagliflozin, a sodium glucose cotransporter 2 (SGLT2) inhibitor, as add-on to metformin in type 2 diabetes with mild hyperglycaemia. Diabetes Obes Metab. 2013;15(12):1154-1160.

35. Ferrannini E, Berk A, Hantel S, et al. Long-term safety and efficacy of empagliflozin, sitagliptin, and metformin: an active-controlled, parallelgroup, randomized, 78-week open-label extension study in patients with type 2 diabetes. Diabetes Care. 2013;36(12):4015-4021.

36. Haring HU, Merker L, Seewaldt-Becker E, et al. Empagliflozin as add-on to metformin in patients with type 2 diabetes: a 24-week, randomized, double-blind, placebo-controlled trial. Diabetes Care. 2014;37(6):1650-1659.

37. Merker L, Haring HU, Christiansen AV, et al. Empagliflozin as add-on to metformin in people with Type 2 diabetes. Diabet Med. 2015;32(12):1555-1567.

38. Ridderstrale M, Andersen KR, Zeller C, et al. Comparison of empagliflozin and glimepiride as add-on to metformin in patients with type 2 diabetes: a 104-week randomised, active-controlled, double-blind, phase 3 trial. Lancet Diabetes Endocrinol. 2014;2(9):691-700.
39. Haring HU, Merker L, Seewaldt-Becker E, et al. Empagliflozin as addon to metformin plus sulfonylurea in patients with type 2 diabetes: a 24-week, randomized, double-blind, placebo-controlled trial. Diabetes Care. 2013;36(11):3396-3404.

40. Haering HU, Merker L, Christiansen AV, et al. Empagliflozin as addon to metformin plus sulphonylurea in patients with type 2 diabetes. Diabetes Res Clin Pract. 2015;110(1):82-90.

41. Kovacs CS, Seshiah V, Swallow R, et al. Empagliflozin improves glycaemic and weight control as add-on therapy to pioglitazone or pioglitazone plus metformin in patients with type 2 diabetes: a 24-week, randomized placebo-controlled trial. Diabetes Obes Metab. 2014;16(2):147-158.

42. Ferrannini E, Muscelli E, Frascerra S, et al. Metabolic response to sodium-glucose cotransporter 2 inhibition in type 2 diabetic patients. J Clin Invest. 2014;124(2):499-508.

43. Friedrich C, Metzmann K, Rose P, Mattheus M, Pinnetti S, Woerle HJ. A randomized, open-label, crossover study to evaluate the pharmacokinetics of empagliflozin and linagliptin after coadministration in healthy male volunteers. Clin Ther. 2013;35(1):A33-A42.

44. Lewin A, DeFronzo RA, Patel S, et al. Initial combination of empagliflozin and linagliptin in subjects with type 2 diabetes. Diabetes Care. 2015;38(3):394-402.

45. DeFronzo RA, Lewin A, Patel S, et al. Combination of empagliflozin and linagliptin as second-line therapy in subjects with type 2 diabetes inadequately controlled on metformin. Diabetes Care. 2015;38(3):384-393.

46. Ross S, Thamer C, Cescutti J, Meinicke T, Woerle HJ, Broedl UC. Efficacy and safety of empagliflozin twice daily versus once daily in patients with type 2 diabetes inadequately controlled on metformin: a 16-week, randomized, placebo-controlled trial. Diabetes Obes Metab. 2015;17(7):699-702.

47. Rosenstock J, Jelaska A, Zeller C, et al. Impact of empagliflozin added on to basal insulin in type 2 diabetes inadequately controlled on basal insulin: a 78-week randomized, double-blind, placebo-controlled trial. Diabetes Obes Metab. 2015;17(10):936-948.

48. Rosenstock J, Jelaska A, Frappin G, et al. Improved glucose control with weight loss, lower insulin doses, and no increased hypoglycemia with empagliflozin added to titrated multiple daily injections of insulin in obese inadequately controlled type 2 diabetes. Diabetes Care. 2014;37(7):1815-1823.

49. Holman RR, Sourij H, Califf RM. Cardiovascular outcome trials of glucose-lowering drugs or strategies in type 2 diabetes. Lancet. 2014;383(9933):2008-2017.

50. Hayward RA, Reaven PD, Emanuele NV; VADT Investigators. Follow-up of glycemic control and cardiovascular outcomes in type 2 diabetes. N Engl J Med. 2015;373(10):978.

51. Hong J, Zhang Y, Lai S, et al. Effects of metformin versus glipizide on cardiovascular outcomes in patients with type 2 diabetes and coronary artery disease. Diabetes Care. 2013;36(5):1304-1311.

52. Monami M, Dicembrini I, Nardini C, Fiordelli I, Mannucci E. Effects of glucagon-like peptide-1 receptor agonists on cardiovascular risk: a meta-analysis of randomized clinical trials. Diabetes Obes Metab. 2014;16(1):38-47.

53. Seong JM, Choi NK, Shin JY, et al. Differential cardiovascular outcomes after dipeptidyl peptidase-4 inhibitor, sulfonylurea, and pioglitazone therapy, all in combination with metformin, for type 2 diabetes: a population-based cohort study. PLoS One. 2015;10(5):e0124287.

54. Chilton R, Tikkanen I, Cannon CP, et al. 4b.02: the sodium glucose cotransporter 2 inhibitor empagliflozin reduces blood pressure and markers of arterial stiffness and vascular resistance in type 2 diabetes. J Hypertens. 2015;33(suppl 1):e53.

55. Chilton R, Tikkanen I, Cannon CP, et al. Effects of empagliflozin on blood pressure and markers of arterial stiffness and vascular resistance in patients with type 2 diabetes. Diabetes Obes Metab. 2015;17(12):1180-1193.

56. Zinman B, Wanner C, Lachin JM, et al. Empagliflozin, cardiovascular outcomes, and mortality in type 2 diabetes. $N$ Engl $\mathrm{J} \mathrm{Med}$. 2015;373(22):2117-2128 
57. McMurray JJ, Gerstein HC, Holman RR, Pfeffer MA. Heart failure: a cardiovascular outcome in diabetes that can no longer be ignored. Lancet Diabetes Endocrinol. 2014;2(10):843-851.

58. Nichols GA, Gullion CM, Koro CE, Ephross SA, Brown JB. The incidence of congestive heart failure in type 2 diabetes: an update. Diabetes Care. 2004;27(8):1879-1884.

59. Scirica BM, Bhatt DL, Braunwald E, et al. Saxagliptin and cardiovascular outcomes in patients with type 2 diabetes mellitus. $N$ Engl J Med. 2013;369(14):1317-1326.

60. Nesto RW, Bell D, Bonow RO, et al. Thiazolidinedione use, fluid retention, and congestive heart failure: a consensus statement from the American Heart Association and American Diabetes Association. October 7, 2003. Circulation. 2003;108(23):2941-2948.

61. Inzucchi SE, Zinman B, Wanner C, et al. SGLT-2 inhibitors and cardiovascular risk: proposed pathways and review of ongoing outcome trials. Diab Vasc Dis Res. 2015;12(2):90-100.

62. Cheeseman C. Solute carrier family 2, member 9 and uric acid homeostasis. Curr Opin Nephrol Hypertens. 2009;18(5):428-432.

63. Kanbay M, Jensen T, Solak Y, et al. Uric acid in metabolic syndrome: from an innocent bystander to a central player. Eur J Intern Med. 2016;29:3-8.

64. Uchida S, Chang WX, Ota T, et al. Targeting uric acid and the inhibition of progression to end-stage renal disease-a propensity score analysis. PLoS One. 2015;10(12):e0145506.

65. Barnett AH, Mithal A, Manassie J, et al. Efficacy and safety of empagliflozin added to existing antidiabetes treatment in patients with type 2 diabetes and chronic kidney disease: a randomised, double-blind, placebo-controlled trial. Lancet Diabetes Endocrinol. 2014;2(5):369-384.

66. Brunk D. Empagliflozin benefited type 2 diabetes patients with CKD. Clinical Endocrinology News Digital Network. 2015.
67. Cherney D, Cooper M, Tikkanen I, et al. 4b.01: contrasting influences of renal function on blood pressure and $\mathrm{HbA} 1 \mathrm{C}$ reductions with empagliflozin in patients with type 2 diabetes and hypertension. J Hypertens. 2015;33(Suppl 1):e53.

68. Vivian EM. Sodium-glucose co-transporter 2 (SGLT2) inhibitors: a growing class of antidiabetic agents. Drugs Context. 2014;3: 212264.

69. Bolinder J, Ljunggren Ö, Johansson L, et al. Dapagliflozin maintains glycaemic control while reducing weight and body fat mass over 2 years in patients with type 2 diabetes mellitus inadequately controlled on metformin. Diabetes Obes Metab. 2014;16(2):159-169.

70. Cefalu WT, Leiter LA, Yoon KH, et al. Efficacy and safety of canagliflozin versus glimepiride in patients with type 2 diabetes inadequately controlled with metformin (CANTATA-SU): 52 week results from a randomised, double-blind, phase 3 non-inferiority trial. Lancet. 2013;382(9896):941-950.

71. Taylor SI, Blau JE, Rother KI. SGLT2 inhibitors may predispose to ketoacidosis. J Clin Endocrinol Metab. 2015;100(8):2849-2852.

72. Taylor SI, Blau JE, Rother KI. Possible adverse effects of SGLT2 inhibitors on bone. Lancet Diabetes Endocrinol. 2015;3(1):8-10.

73. Cherney DZ, Perkins BA, Soleymanlou N, et al. Renal hemodynamic effect of sodium-glucose cotransporter 2 inhibition in patients with type 1 diabetes mellitus. Circulation. 2014;129(5):587-597.

74. Schernthaner G, Mogensen CE, Schernthaner GH. The effects of GLP-1 analogues, DPP-4 inhibitors and SGLT2 inhibitors on the renal system. Diab Vasc Dis Res. 2014;11(5):306-323.

75. Vallon V, Gerasimova M, Rose MA, et al. SGLT2 inhibitor empagliflozin reduces renal growth and albuminuria in proportion to hyperglycemia and prevents glomerular hyperfiltration in diabetic Akita mice. Am J Physiol Renal Physiol. 2014;306(2):F194-F204.
Clinical Pharmacology: Advances and Applications

\section{Publish your work in this journal}

Clinical Pharmacology: Advances and Applications is an international, peer-reviewed, open access journal publishing original research, reports, reviews and commentaries on all areas of drug experience in humans. The manuscript management system is completely online and includes a very quick and fair peer-review system, which is all easy to use.

\section{Dovepress}

Visit http://www.dovepress.com/testimonials.php to read real quotes from published authors. 